\title{
THE
}

1989

\section{The Average Distribution of Volume Transport and Potential Vorticity with Temperature at Three Sections across the Gulf Stream}

\author{
K. D. Leaman \\ E. Johns \\ Hans Thomas Rossby \\ University of Rhode Island, trossby@uri.edu
}

Follow this and additional works at: https://digitalcommons.uri.edu/gsofacpubs

Terms of Use

All rights reserved under copyright.

\section{Citation/Publisher Attribution}

Leaman, K. D., Johns, E., \& Rossby, T. (1989). The Average Distribution of Volume Transport and Potential Vorticity with Temperature at Three Sections across the Gulf Stream. J. Phys. Oceanogr., 19(1), 36-51. doi: 10.1175/1520-0485(1989)0192.0.CO;2

Available at: https://doi.org/10.1175/1520-0485(1989)019<0036:TADOVT>2.0.C0;2

This Article is brought to you for free and open access by the Graduate School of Oceanography at DigitalCommons@URI. It has been accepted for inclusion in Graduate School of Oceanography Faculty Publications by an authorized administrator of DigitalCommons@URI. For more information, please contact digitalcommons-group@uri.edu. 


\title{
The Average Distribution of Volume Transport and Potential Vorticity with Temperature at Three Sections across the Gulf Stream
}

\author{
K. D. LEAMAN \\ Rosenstiel School of Marine \& Atmospheric Science, University of Miami, Miami, Florida \\ E. JOHNS* \\ Cooperative Institute of Marine and Atmospheric Studies, University of Miami, Miami, Florida
}

T. RossBY

University of Rhode Island, Narragansett Bay Campus, Kingston, Rhode Island

(Manuscript received 6 November 1987, in final form 31 March 1988)

\section{ABSTRACT}

Average cross sections of downstream velocity and temperature, obtained using PEGASUS current profilers at three locations along the Gulf Stream, have been partitioned into $2.5^{\circ} \mathrm{C}$ temperature intervals to examine the distribution of transport increase versus temperature between the two southern sections $\left(27^{\circ}\right.$ and $\left.29^{\circ} \mathrm{N}\right)$ and off Cape Hatteras $\left(73^{\circ} \mathrm{W}\right.$ ). Between $27^{\circ}$ and $29^{\circ} \mathrm{N}$ the total transport of the Florida Current over the sections increased only by about $3 \times 10^{6} \mathrm{~m}^{3} \mathrm{~s}^{-1}(3 \mathrm{~Sv})$ but the current broadens by about $50 \%$. By Cape Hatteras, the transport has increased nearly three-fold to $93.7 \mathrm{~Sv}$, of which two-thirds of the increase is contained in the $19.5^{\circ}-17.0^{\circ} \mathrm{C}$ (" $\left.18^{\circ} "\right)$ layer and in water colder than the $7^{\circ} \mathrm{C}$ "sill" temperature found at $27^{\circ} \mathrm{N}$.

Cross-stream distributions of layer transport, potential vorticity, and thickness are estimated. At each section, the $10 \times 10^{-7} \mathrm{~m}^{-1} \mathrm{~s}^{-1}$ contour tends to be a boundary (independent of temperature) between the region of relatively uniform layer potential vorticity on the anticyclonic (offshore) side of the current and an area with high lateral potential vorticity gradients on the cyclonic (onshore) side. In the colder $\left(<7^{\circ} \mathrm{C}\right)$ waters off Cape Hatteras, layer potential vorticity also tends to be uniform at $\sim 5 \times 10^{-7} \mathrm{~m}^{-1} \mathrm{~s}^{-1}$. Layer potential vorticity in the $18^{\circ}$ layer is quite uniform with minimum values $\sim 3.5 \times 10^{-7} \mathrm{~m}^{-1} \mathrm{~s}^{-1}$ at $27^{\circ}$ and $29^{\circ} \mathrm{N}$ and somewhat less off Cape Hatteras, which is close to where $18^{\circ} \mathrm{C}$ water is formed in the wintertime. At Cape Hatteras this same layer shows a peak in transport/unit width at the point where the layer begins to thin as one moves into the Gulf Stream core from the southeast. A simple model based on conservation of layer potential vorticity is proposed to describe this transport structure.

\section{Introduction}

One of the most distinctive features of the Gulf Stream system (including the Florida Current) is the large increase in transport by the current as it flows northward along the eastern U.S. coast. As early as the late 19th century, Pillsbury (1891) was able to obtain direct current measurements in the Florida Current at about the latitude of Miami. A reanalysis of these data (Schmitz and Richardson 1968) shows that Pillsbury's

\footnotetext{
- Present address: National Oceanic and Atmospheric Administration, Atlantic Oceanographic and Meteorological Laboratories, Miami, Florida 33149.

Corresponding author address: Dr. Kevin D. Leaman, Rosenstiel School of Marine \& Atmospheric Science, Division of Meteorology and Physical Oceanography, 4600 Rickenbacker Causeway, Miami, FL 33149-1098.
}

average transport came to about $25 \times 10^{6} \mathrm{~m}^{3} \mathrm{~s}^{-1}$ (Sv $\left.10^{6} \mathrm{~m}^{3} \mathrm{~s}^{-1}\right)$, although this result was obtained by linear extrapolation to zero speed at the bottom (Pillsbury's observations extend only to $230 \mathrm{~m}$ depth). These same authors pointed out that in fact, direct, full-depth current data show that the Florida Current penetrates essentially to the bottom and that its total transport is about $32 \mathrm{~Sv}$.

On the other hand, early hydrographic data on sections across the Gulf Stream off Cape Hatteras (e.g., Iselin 1940) suggested that using the geostrophic method with a reference level of $2000 \mathrm{~m}$, the transport of the Gulf Stream off Cape Hatteras could attain values of up to $93 \mathrm{~Sv}$. A review of the existing literature shows a wide range of transport estimates derived from the geostrophic (or dynamic) method off Cape Hatteras, in part due to the well-known limitations of this approach. In particular, later observations demonstrated that the Gulf Stream could penetrate to the bottom in this region $\left(73^{\circ} \mathrm{W}\right)$. 
The most obvious question that arose from these observations was the manner in which this transport increase took place and the distribution and structure of this increase, both in physical space and with respect to the transport of water at different temperatures by the Gulf Stream. To examine the downstream transport increase in the Florida Current, direct transport measurements by dropsonde (Richardson and Schmitz 1965 ) were made in the period 1965-68 along a series of sections between the Florida Keys and Cape Fear, North Carolina (Richardson et al. 1969). It was found that transport increased from 29.6 Sv off the keys to approximately $53 \mathrm{~Sv}$ off Cape Fear. Also, the transport increase tended to be constant with depth when computed over $100 \mathrm{~m}$ depth bins (roughly the vertical resolution of the dropsondes), suggesting that this increase was primarily barotropic. The absence of temperature data did not allow the transport contributed within different temperature intervals to be estimated from these data.

More recently, three independent, multiyear experiments, using virtually identical instrumentation, were carried out in the Florida Current and in the Gulf Stream off Cape Hatteras in the early 1980 s to observe both the mean structure and variability in the temperature and velocity fields of this current. All velocity and temperature data were collected using a free-falling, acoustically tracked profiler of horizontal current and temperature called PEGASUS (Spain et al. 1981). One significant advantage of this profiler is that absolute (i.e., with reference to a geographically fixed coordinate system ) currents are measured, in contrast to the relative currents obtained from (unreferenced) geostrophic profiles. Briefly, this instrument uses a pair of acoustic transponders deployed and accurately located on the bottom to track its path as it descends at 0.4$0.6 \mathrm{~m} \mathrm{~s}^{-1}$ upon release from the research vessel, releases a set of weights at an intermediate depth or at the bottom, and once again rises to the sea surface. Every 8 seconds (16 sec in deeper water) the instrument sends out an acoustic pulse at $10 \mathrm{kHz}$, to which the transponders respond at two other frequencies (usually 12.5 and $12.0 \mathrm{kHz}$ ). By timing the round-trip acoustic travel times between itself and each transponder, as well as recording pressure (and temperature) at each 8 or 16 sec measurement interval, the profiler can track itself through the water column. Once in the lab, the travel time and pressure data are combined to obtain horizontal displacements of the profiler. These displacements are then least-squares fit to a 7-point straight line for $8 \mathrm{sec}$ sampling (or a centered quadratic in the case of $16 \mathrm{sec}$ sampling) to obtain absolute horizontal velocities. In the three experiments described below, the only real differences in the method used at each cross-section are related to the sampling interval ( 8 or 16 secs) and the depth of the profile (above-bottom or bottom release). (For example, at a $16 \mathrm{sec}$ rate vertical resolution is roughly one-half that available at $8 \mathrm{sec}$.
A quadratic fit is found to improve velocity estimates at the slower rate when the horizontal displacement curves exhibit significant curvature over the measurement interval. At higher resolution $(8 \mathrm{sec})$ a linear fit has been found to be adequate.)

Some results from these experiments have already appeared in the literature, and the background of the experiments will only be briefly summarized in the next section. The main purpose of this paper will be to describe the variations in the mean transport and potential vorticity fields as observed by these experiments at three downstream cross sections. These variations can be described both in physical space as well as with reference to different temperature intervals within the current.

\section{Brief description of the three experiments}

a. $\operatorname{STACS}\left(27^{\circ} \mathrm{N}\right)$

The Sub-Tropical Atlantic Climate Studies (STACS) Florida Current experiment lasted from April 1982 to July 1984. A primary goal of this experiment was to evaluate the utility of various remote techniques (submarine cables, tide gauges, etc.) in monitoring longperiod fluctuations in Florida Current transport (Molinari 1983). A fairly dense array of direct instrumentation (current meter moorings, PEGASUS stations, etc.) was deployed to provide calibration input for these remote methods. Results from this work have been published in a series of papers (Mayer et al. 1984; Molinari et al. 1985a,b; Lee et al. 1985; Larsen and Sanford 1985; Maul et al. 1985; Schott and Zantopp 1985; Leaman et al. 1987a,b; Johns and Schott 1987).

Results from 16 PEGASUS cruises to a line of nine PEGASUS stations along $27^{\circ} \mathrm{N}$ (Fig. 1) are summarized in Leaman et al. (1987b). In this experiment all PEGASUS profiles were made to the bottom of the Straits of Florida with an $8 \mathrm{sec}$ sampling rate. The horizontal separation between stations was approximately $10 \mathrm{~km}$.

\section{b. $\operatorname{FACTS}\left(29^{\circ} \mathrm{N}\right)$}

The Florida Atlantic Coast Transport Study (FACTS) was initiated by the State of Florida and the Minerals Management Service to evaluate the possible impact of Gulf Stream fluctuations in carrying surface pollutants (oil) toward coastal areas in a region being considered for oil leases (Maul 1985). Results from this experiment are described in Leaman (1986) and Zantopp et al. (1987).

From April 1984 to January 1986 a total of 7 PEGASUS cruises were made to the line of stations shown in Fig. 1. Up to four repeated cross sections were obtained during each cruise. The six stations deployed at $29^{\circ} \mathrm{N}$ for this experiment ranged in horizontal separation from $10 \mathrm{~km}$ on the inshore edge to roughly 30 


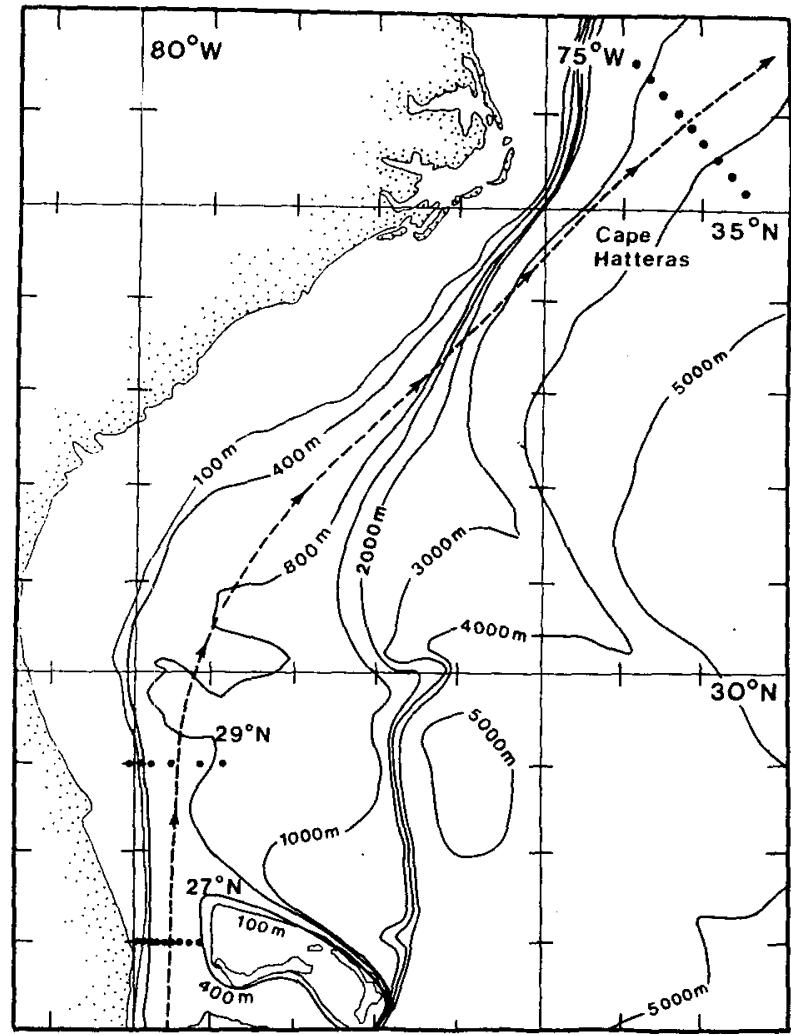

FIG. 1. Locations of PEGASUS absolute velocity and temperature cross sections at $27^{\circ} \mathrm{N}$ (STACS), $29^{\circ} \mathrm{N}$ (FACTS), and off Cape Hatteras. The mean path of the Gulf Stream is indicated by the dashed line.

$\mathrm{km}$ between the easternmost stations. An $8 \mathrm{sec}$ sampling rate was used and all absolute velocity-temperature profiles were taken to the bottom.

\section{c. Cape Hatteras $\left(73^{\circ} \mathrm{W}\right)$}

From September 1980 to May 1983, 16 PEGASUS sections were obtained near $73^{\circ} \mathrm{W}$ (Fig. 1) off Cape Hatteras (Halkin and Rossby 1985; Rossby 1987; Rago and Rossby 1987). In contrast to the previous two cases, the greater depths in the Cape Hatteras experiment required that the profiler record only every 16 $\mathrm{sec}$ (thereby halving the vertical resolution to $\sim 8 \mathrm{~m}$ ). Also, in most cases the profile was obtained to within $75 \%-80 \%$ of full depth. (For this experiment mid-depth pressure releases were used-therefore, profiles were made as close to the bottom as was safe to avoid the possibility of "stranding" the profiler on the bottom before the release could function). Nine stations were included in this line, at horizontal separations of approximately $25 \mathrm{~km}$.

A major difference in the Cape Hatteras data relative to the other two data sets is that at $73^{\circ} \mathrm{W}$ the Gulf Stream was found to execute significant lateral shifts and changes in downstream direction due to mean- dering of the current as a whole. An Eulerian average under such conditions will tend to broaden and blur the current structure. Therefore, Halkin and Rossby (1985) developed a method to remove substantially the effects of meandering and thereby obtain a better description of the downstream velocity and thermal structure in so-called "stream" coordinates. The average Cape Hatteras data analyzed here are with reference to these stream coordinates.

\section{Analysis of averaged velocity and temperature data at three cross-sections}

The structures of the averaged (over all data) crosssections of downstream velocity and temperature for the STACS, FACTS, and Cape Hatteras PEGASUS lines are given respectively in Leaman et al. (1987b), Leaman (1986), and Halkin and Rossby (1985). The downstream velocity and temperature data are replotted in Figs. 2-4 using a common ratio of vertical to horizontal distance scales. At $27^{\circ}$ and $29^{\circ} \mathrm{N}$, the downstream direction is within $5^{\circ}$ of geographic north. At $73^{\circ} \mathrm{W}$ the average downstream direction is approximately $51^{\circ} \mathrm{T}$.

At $27^{\circ}$ and $29^{\circ} \mathrm{N}$ the mean profiles at each station were interpolated vertically every $10 \mathrm{~m}$ (the original vertical resolution was $\sim 4 \mathrm{~m}$ ) between the surface and bottom. At Cape Hatteras, the data were interpolated every $25 \mathrm{~m}$ vertically. This larger interpolation step was justified both by the larger scales of the mean Gulf Stream at this location as well as by the lower vertical resolution of the original PEGASUS data there. Also, at Cape Hatteras mean velocities were linearly extrapolated between the deepest available data point and zero mean velocity at the bottom while temperatures were extrapolated to the bottom using a constant value of the coldest (deepest) data point.

Along both southern sections (except for the eastern end at $29^{\circ} \mathrm{N}$ ) station separations were typically $10 \mathrm{~km}$, whereas at Cape Hatteras this increased to $25 \mathrm{~km}$. To facilitate further analysis, the average downstream quantities at each section were interpolated horizontally to a set of "pseudostations" with a common horizontal separation of $10 \mathrm{~km}$. For the STACS and western FACTS sections, the locations of these pseudostations fell on average close to the locations of the real stations. At Cape Hatteras the $10 \mathrm{~km}$-grid section is obviously oversampled. As a consistency check, transport to 2000 m was computed on the $10 \mathrm{~km}$ grid and was found to agree within $2 \%$ of the value computed directly from the stations (87.8 Sv) by Halkin and Rossby (1985). Also, in the southern sections only the transport spanned by the PEGASUS stations is computed, resulting in somewhat lower values than obtained by extrapolation to the boundaries (Leaman et al. 1987b).

Based on the $10 \mathrm{~km}$ interpolated stations, the total widths of the STACS, FACTS, and Cape Hatteras sec- 

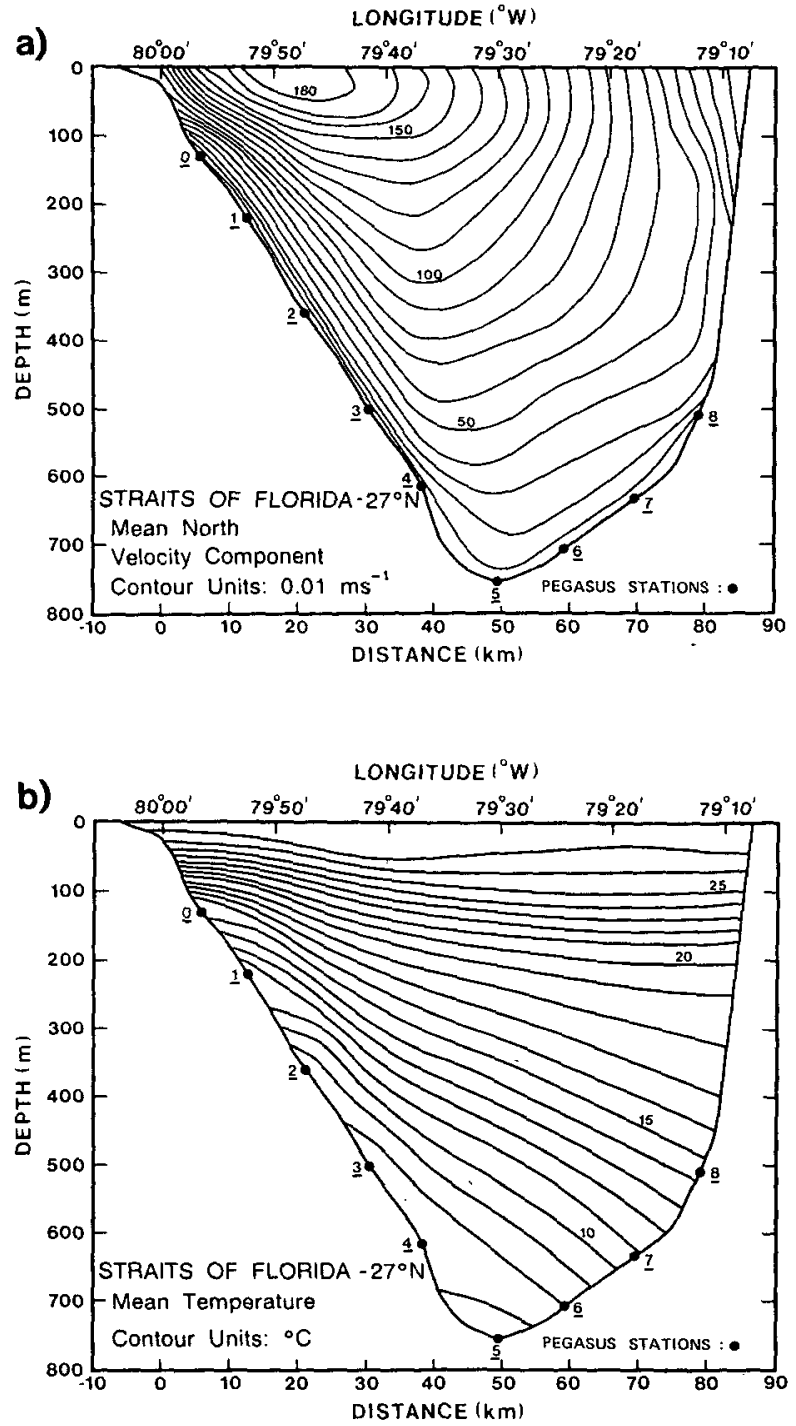

Fig. 2. Contours of average downstream (north) velocity (a) and temperature (b) of the Florida Current at $27^{\circ} \mathrm{N}$.

tions are respectively $70 \mathrm{~km}, 120 \mathrm{~km}$ and $200 \mathrm{~km}$. At both $27^{\circ}$ and $29^{\circ} \mathrm{N}$ the section essentially covered the total current, with small depth-averaged velocities at both the western (Continental Shelf) and eastern (Little Bahama Bank at $27^{\circ} \mathrm{N}$, an open boundary at $29^{\circ} \mathrm{N}$ ) ends of the section. At Cape Hatteras, where the Gulf Stream is not bounded on either side by topography, defining the "width" of the current is more difficult. Halkin and Rossby (1985) defined the Gulf Stream boundaries as those locations where the downstream transport/unit width between the surface and $2000 \mathrm{~m}$ became negative as one left the current at either side. The same definition of width will be used below; however, we emphasize that width defined in this manner may change depending on the depth to which transport integrals are computed.

\section{Method of computing layer transport, thickness, and potential vorticity}

The manner in which the above quantities have been computed is indicated in Fig. 5. Respectively, $V(x, z)$ and $T(x, z)$ are the average downstream velocity component and temperature at cross-stream distance $x$ and depth $z$. Interpolated stations (numbered $n$ ) are located at $x_{n}=0,10,20, \cdots \mathrm{km}$ with station separation $\Delta x_{n}$ $=x_{n+1}-x_{n}=10 \mathrm{~km}$. Temperature layer boundaries are at $T_{j}=\cdots, 22.0,19.5,17.0, \cdots{ }^{\circ} \mathrm{C}$ with a separation between boundaries of $\Delta T_{j}=T_{j}-T_{j+1}$ $=2.5^{\circ} \mathrm{C}$. Computed values for a given station pair $(n$, $n+1)$ and temperature interval $\left(T_{j}, T_{j+1}\right)$ are assumed to be located at the midpoint of that interval; that is, at $\bar{x}_{n}=\left(x_{n}+x_{n+1}\right) / 2$ and $\bar{T}_{j}=\left(T_{j}+T_{j+1}\right) / 2$. The $\bar{T}_{j}$ layer thickness at station $n$ is

$$
h\left(x_{n}, \bar{T}_{j}\right)=z\left(x_{n}, T_{j+1}\right)-z\left(x_{n}, T_{j}\right)
$$

and the transport in that layer between stations $n$ and $n+1$ is

$$
F\left(\bar{x}_{n}, \bar{T}_{j}\right)=\int_{x_{n}}^{x_{n+1}} \int_{z\left(x, T_{j}\right)}^{z\left(x, T_{j+1}\right)} v(x, z) d z d x
$$

Total transport values for layer $\bar{T}_{j}$ are then obtained by summing the $F\left(\bar{x}_{n}, \bar{T}_{j}\right)$ over all values of $\bar{x}_{n}$ :

$$
F_{T}\left(\bar{T}_{j}\right)=\sum_{\bar{x}_{n}} F\left(\bar{x}_{n}, \bar{T}_{j}\right)
$$

The average $2.5^{\circ} \mathrm{C}$-layer thickness and potential vorticity between stations are computed as follows. Using the definition of layer thickness at a horizontal grid point $x_{n}$ given above [Eq. (1)], we define the average $\bar{T}_{j}$ layer thickness between grid points $n$ and $n$ +1 as.

$$
H\left(\bar{x}_{n}, \bar{T}_{j}\right)=\left[h\left(x_{n}, \bar{T}_{j}\right)+h\left(x_{n+1}, \bar{T}_{j}\right)\right] / 2
$$

and the layer potential vorticity as

$P\left(\bar{x}_{n}, \bar{T}_{j}\right)=\frac{f+\left[\bar{v}\left(x_{n+1}, \bar{T}_{j}\right)-\bar{v}\left(x_{n}, \bar{T}_{j}\right)\right] / \Delta x_{n}}{H\left(\bar{x}_{n}, \bar{T}_{j}\right)}$

where

$$
\bar{v}\left(x_{n}, \bar{T}_{j}\right)=\frac{1}{h\left(x_{n}, \bar{T}_{j}\right)} \int_{z\left(x_{n}, T_{j}\right)}^{z\left(x_{n}, T_{j+1}\right)} v\left(x_{n}, z\right) d z
$$

is the vertically averaged downstream velocity in layer $\bar{T}_{j}$ at location $x_{n}$ and $f$ is the local Coriolis parameter. (Note that in the absence of information on downstream $(y)$ gradients, the contribution $\partial u / \partial y$ to the relative vorticity, $\xi(=\partial v / \partial x-\partial u / \partial y$, with $u$ the crossstream velocity component), has been ignored).

The layer potential vorticity used here differs from the "potential vorticity", $Q$, usually computed for continuous stratification:

$$
Q=-\left(1 / \rho_{0}\right)(f+\xi) \frac{\partial \rho_{\theta}}{\partial z} .
$$



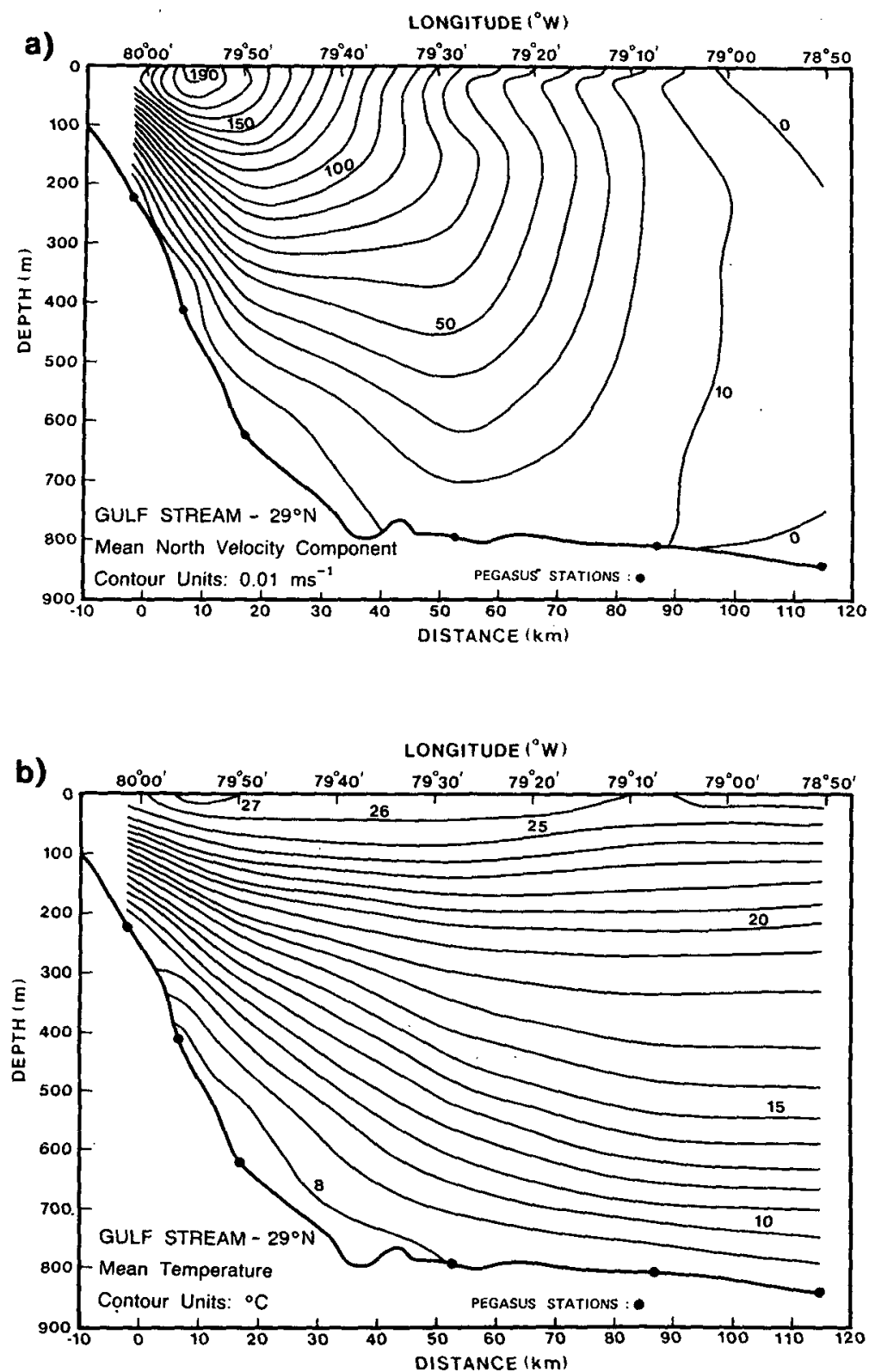

FIG. 3. As in Fig. 2 but at $29^{\circ} \mathrm{N}$.

In this expression, $\rho_{0}$ is a reference density (taken as 1 $\mathrm{g} \mathrm{cm}^{-3}$ in cgs units) and $\partial \rho_{\theta} / \partial z$ is the vertical gradient of potential density. Various investigators (McDowell et al. 1982; McWilliams 1983) have shown maps or other representations of $Q$ (or a close variant thereof) for the North Atlantic Ocean. In general, these fields are computed from hydrographic data and thus do not include the relative vorticity. Although a limited number of CTD sections were made along the PEGASUS line described here, the only hydrographic parameter measured directly by PEGASUS is temperature. Therefore, it will be useful to digress briefly to describe an approximate method for converting our layer po- tential vorticities, presented in section 6 , to values for $Q$ given in other sources.

The factor $\partial p_{\theta} / \partial z=10^{-3} \partial \sigma_{\theta} / \partial z$ [where $\sigma_{\theta}=\left(\rho_{\theta}-1\right)$ $\left.\times 10^{3}\right]$ can be approximated by $10^{-3} \Delta \sigma_{\theta} / H$, where $H$ is the distance between two temperature surfaces [Eq. (4)] and $\Delta \sigma_{\theta}$ is the difference in $\sigma_{\theta}$ between the same surfaces. Values of $\sigma_{\theta}$ as a function of temperature are plotted in Fig. 6, using a mean $T-S$ curve for the western North Atlantic (MODE-I Atlas Group 1977; Zantopp and Leaman 1984). (Of course, the stability of $\sigma_{\theta}$ values is directly governed by the tightness of the $T-S$ curve; this is mainly a problem above $19^{\circ}-20^{\circ} \mathrm{C}$, and also above about $11^{\circ} \mathrm{C}$ in the slope water in win- 

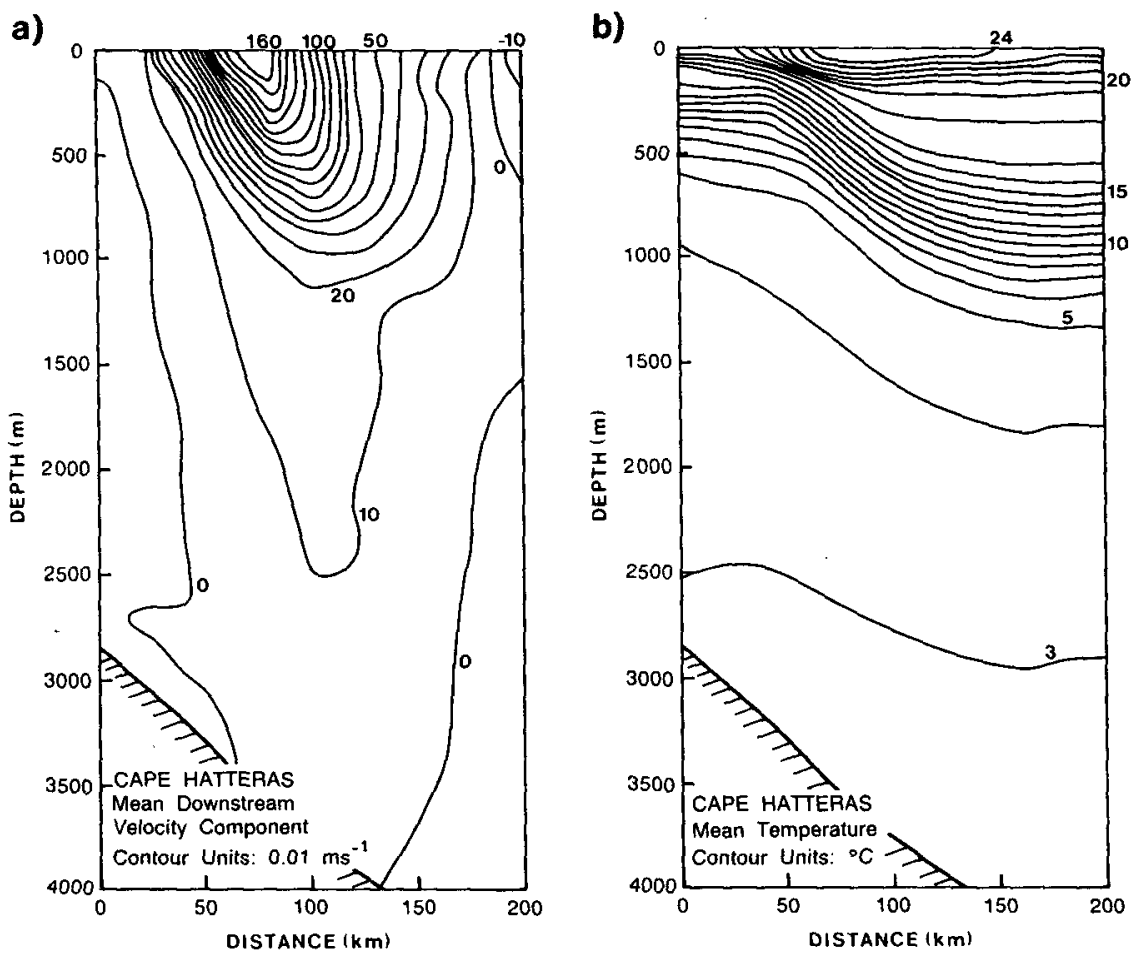

FIG. 4. As in Fig. 2 but off Cape Hatteras.

ter). Thus, the layer potential vorticities, multiplied by $10^{-3} \Delta \sigma_{\theta} / \rho_{0}$, are approximately equivalent to $Q$. For example, at Cape Hatteras the layer potential vorticity in the $4.5^{\circ}-7.0^{\circ} \mathrm{C}$ interval is relatively uniform at about

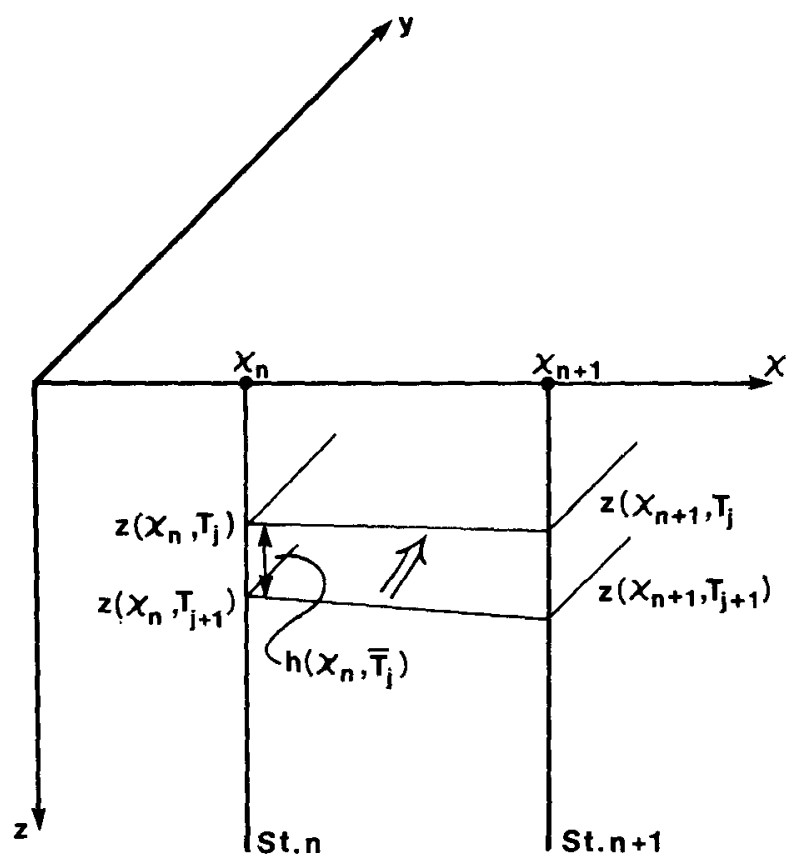

FIG. 5. Method of computing layer transport, thickness and potential vorticity between stations.
$5 \times 10^{-7} \mathrm{~m}^{-1} \mathrm{~s}^{-1}\left(5 \times 10^{-9} \mathrm{~cm}^{-1} \mathrm{~s}^{-1}\right)$ as shown in Fig. $11 \mathrm{~b}$ and discussed below in section 6 . This layer overlaps the potential vorticity between the $\sigma_{\theta}=27.3$ and 27.6 surfaces computed by McDowell et al. (1982; Fig. 8). Fig. 6 shows that $\Delta \sigma_{\theta}$ for the $4.5^{\circ}-7.0^{\circ} \mathrm{C}$ layer is 0.26 . Thus from our data, $Q=\left(0.26 \times 10^{-3}\right)(5$ $\left.\times 10^{-9}\right)=13 \times 10^{-13} \mathrm{~cm}^{-1} \mathrm{~s}^{-1}$, which is quite consistent with McDowell's values for this layer [(12.515.0) $\times 10^{-13} \mathrm{~cm}^{-1} \mathrm{~s}^{-1}$ ].

Finally we point out that, even with the above approximation, $Q[\mathrm{Eq} .(7)]$ is not strictly equivalent to $P$ [Eq. (5)]. If we assume that the vertical and crossstream velocity components are zero and ignore downstream variations, it can be shown from Ertel's (1942) conservation theorem that the term $\rho_{0}{ }^{-1}(\partial v /$ $\partial z)\left(\partial \rho_{\theta} / \partial x\right)$ should be included in the potential vorticity. This term is ignored in the expression for $Q$ above but is, by our method of computation, included in $P$. Nevertheless, it is still reasonable to compare these two versions of potential vorticity since, as one moves southeastward from the Gulf Stream into the North Atlantic gyre, density surfaces become level $\left(\partial \rho_{\theta} / \partial x \rightarrow\right.$ $0)$ and the two versions become equivalent.

\section{The structure of downstream transport increases}

Two different approaches are used in this section to examine the distribution of Gulf Stream transport across the three sections. In the first, total transport is resolved into $2.5^{\circ} \mathrm{C}$ temperature intervals, while in the 


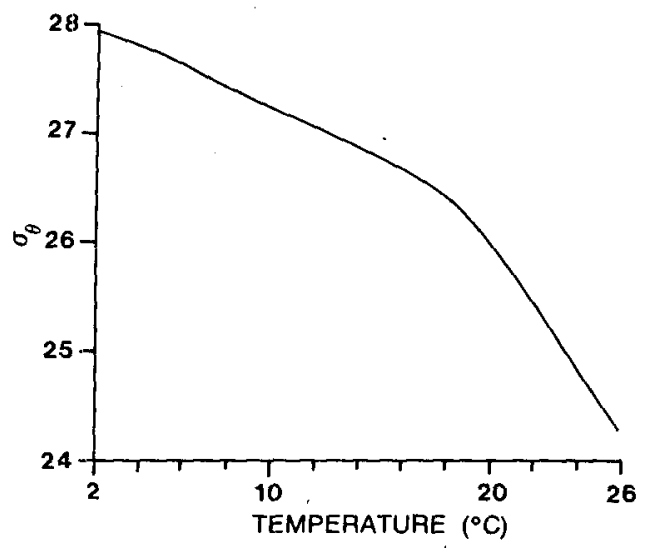

FlG. 6. Values of potential density $\left(\sigma_{\theta}\right)$ as a function of temperature, computed from a mean $T-S$ distribution with depth in the western North Atlantic. These values can be used approximately to convert the layer potential vorticity computed here to " $Q$ " values used elsewhere (McDowell et al. 1982).

second the cross-stream distribution of total transport is emphasized.

\section{a. Transport in $2.5^{\circ} \mathrm{C}$ temperature intervals}

The average total transport $F_{T}\left(\bar{T}_{j}\right)$, at the three sections in $2.5^{\circ} \mathrm{C}$ intervals; $2^{\circ}-4.5^{\circ} \mathrm{C}, 4.5^{\circ}-7^{\circ} \mathrm{C}$, etc. (chosen to agree with Worthington 1976) is shown in Fig. 7 and summarized in Table 1. Although we are interested here only in the mean field, it is worth noting that the standard deviations of values shown in Fig. 7 (computed on a cruise-by-cruise basis) are typically about $15 \%$ of the average values.

At Cape Hatteras, the solid line in Fig. 7 refers to transport computed to the bottom as described above, while, for comparison with Halkin and Rossby (1985), the dashed line shows transport at depths $\leqslant 2000 \mathrm{~m}$. Over $2000 \mathrm{~m}$ the width of the Gulf Stream, as defined above, was $170 \mathrm{~km}$. For Cape Hatteras transport estimated over the total water column, this width reduces to $160 \mathrm{~km}$ due to the existence of near-bottom counterflow in the deeper part of the section. Total transport within the Gulf Stream at Cape Hatteras is $86.8 \mathrm{~Sv}$ to $2000 \mathrm{~m}$ or $93.7 \mathrm{~Sv}$ to the bottom. Total transports within the station lines at $27^{\circ}$ and $29^{\circ} \mathrm{N}$ are 29.9 and 33.2 Sv, respectively.

Curiously, a small ( $<0.1 \mathrm{~Sv}$ ) northward transport of water colder than $7^{\circ} \mathrm{C}$ is evident at $27^{\circ} \mathrm{N}$ (Fig. 2b) but does not appear at $29^{\circ} \mathrm{N}$. A more detailed examination of the STACS section shows that this water is at most $0.2^{\circ}-0.3^{\circ} \mathrm{C}$ colder than $7^{\circ} \mathrm{C}$. A possible explanation for the absence of $<7^{\circ} \mathrm{C}$ water at $29^{\circ} \mathrm{N}$ is that this section was deployed near an east-west oriented ridge about $20-40 \mathrm{~m}$ high relative to the nearby Blake Plateau. This ridge could force an eastward deflection of flow near the bottom.

Transports shown in Fig. 7 can be subdivided into at least four separate regimes. Above $19.5^{\circ} \mathrm{C}$, transport increases slowly over the $120 \mathrm{n}$ mi between $27^{\circ}(14.7$ $\mathrm{Sv}$ ) and $29^{\circ} \mathrm{N}(16.4 \mathrm{~Sv})$, although as might be expected this transport is redistributed in temperature. In fact, even at Cape Hatteras, transport for layers $T \geqslant 19.5^{\circ} \mathrm{C}$ increases only to $19.5 \mathrm{~Sv}$. However, the east-west distribution of transport between $27^{\circ}$ and $29^{\circ} \mathrm{N}$ changes significantly (see below).

For simplicity the next colder layer $\left(19.5^{\circ}-17.0^{\circ} \mathrm{C}\right)$ will be referred to as " $18^{\circ}$ water" with the understanding that this can only be an approximation. Within this layer a peak in transport is apparent even in the Straits of Florida. Between $27^{\circ}$ and $29^{\circ} \mathrm{N}$, transport of $18^{\circ}$ water increases by about $0.9 \mathrm{~Sv}$, or roughly the same amount per $2.5^{\circ} \mathrm{C}$ layer as for warmer temperatures. Between $29^{\circ} \mathrm{N}$ and Cape Hatteras, transport in this layer increases by a further $13.7 \mathrm{~Sv}$, to $19.1 \mathrm{~Sv}$, the largest layer transport in these sections. In the layers $14.5^{\circ} \mathrm{C}-7.0^{\circ} \mathrm{C}$, the transport increase between $27^{\circ} \mathrm{N}$ (or $29^{\circ} \mathrm{N}$ ) and Cape Hatteras is surprisingly uniform at $4-4.5 \mathrm{~Sv}$ per $2.5^{\circ} \mathrm{C}$ interval. Even the increase in the $14.5^{\circ}-17.0^{\circ} \mathrm{C}$ layer ( $6 \mathrm{~Sv}$ ) is more characteristic of the thermocline layers than the $18^{\circ}$ layer immediate above.

Finally, the time-averaged transport increase between $27^{\circ} \mathrm{N}$ and Cape Hatteras for $T \leqslant 7^{\circ} \mathrm{C}$ (the temperature "sill" depth in the Straits of Florida) is approximately $24.8 \mathrm{~Sv}$.

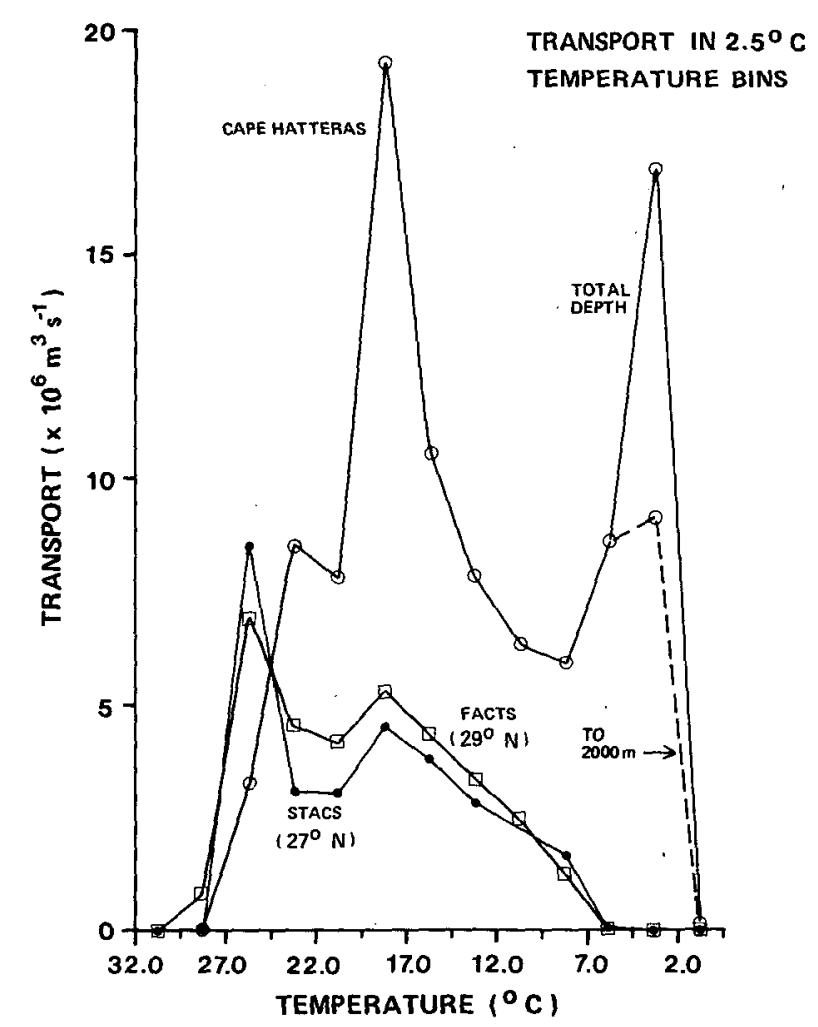

FIG. 7. Average layer transport in $2.5^{\circ} \mathrm{C}$ bins at $27^{\circ}, 29^{\circ} \mathrm{N}$ and Cape Hatteras. 


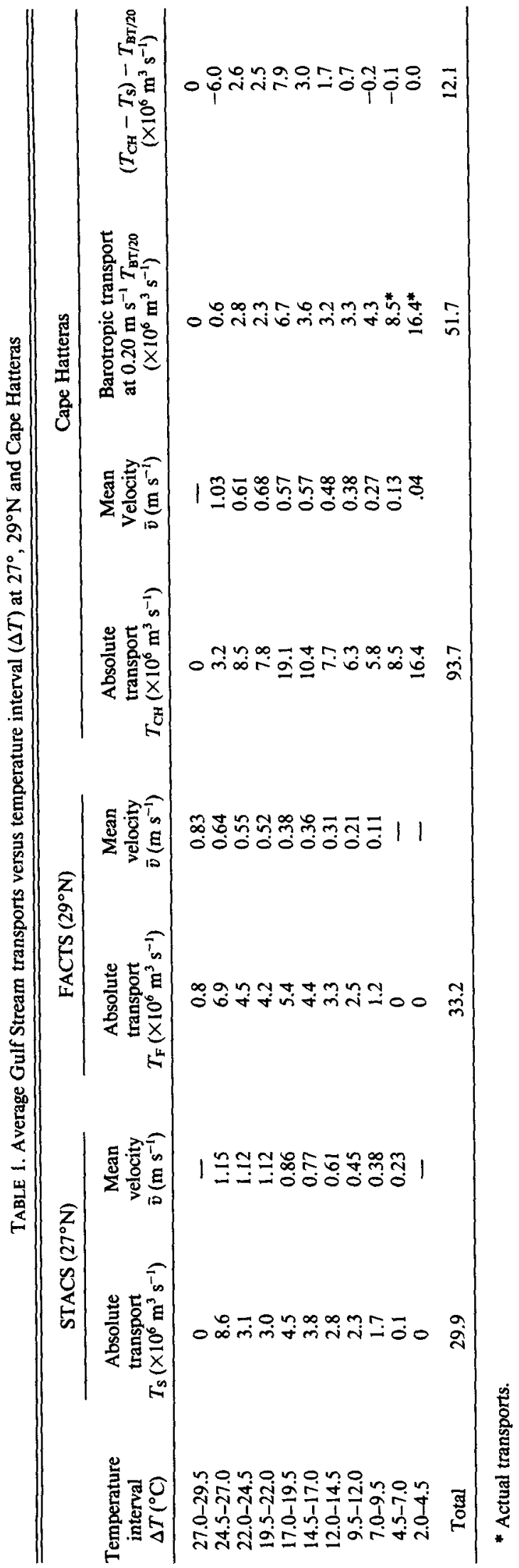

\section{b. Cross-stream structure of transport}

Figure 8 shows the distribution of downstream transport in $10 \mathrm{~km}$ bins across the three sections. No attempt has been made to align the different sections (by using, for example, the locations of an isotherm at a given depth). At the western ends of the $27^{\circ}$ and $29^{\circ} \mathrm{N}$ sections (as well as the eastern end at $27^{\circ} \mathrm{N}$ ), transport was extrapolated to zero (dashed lines) at approximately the physical boundaries of the current. At Cape Hatteras, the first $10-\mathrm{km}$ grid point which showed positive downstream transport when integrated to the bottom was placed at $5 \mathrm{~km}$ distance. The location of the horizontal coordinate origin in Fig. 8 for each section is shown by the vertical arrows at the top of Figs. 9-11a.

Several observations can be made from this figure. First, although there is very little transport increase from $27^{\circ}$ to $29^{\circ} \mathrm{N}$, a clear redistribution in transport has taken place. The Florida Current on average is approximately $50 \%$ wider at the more northern section. Second, the rate of transport increase with cross-stream distance in the cyclonic (western) part of the current is quite similar in the two southern sections, with a value of about $1.8 \mathrm{~Sv} / 10 \mathrm{~km}$ when integrated over 10 $\mathrm{km}$ bins.

Two versions of the corresponding transport curve at Cape Hatteras are shown. The first is simply the total transport in $10 \mathrm{~km}$ bins (indicated as "absolute to bottom" in Fig. 8), and clearly includes both barotropic and baroclinic transport components. In this representation, the rate of maximum cross-stream transport increase on the cyclonic side $(30-50 \mathrm{~km}$ distance in Fig. 6) is somewhat larger than that observed farther south (if one ignores the "tail" in the Cape Hatteras transport curve at small distances).

Another possible "version" of Gulf Stream transport can be obtained by reference to Fig. 4. To a good approximation, the strongly baroclinic part of the Gulf Stream at Cape Hatteras is confined to the region above approximately the $0.2 \mathrm{~m} \mathrm{~s}^{-1}$ isotach of mean downstream velocity. If we compute transport in this region (i.e., from the depth of the $0.2 \mathrm{~m} \mathrm{~s}^{-1}$ isotach to the surface) relative to a $0.2 \mathrm{~m} \mathrm{~s}^{-1}$ "barotropic" downstream velocity, the result (also shown in Fig. 8) emphasizes the baroclinic transport component. The total Cape Hatteras baroclinic transport defined in this manner is $45.9 \mathrm{~Sv}$. In this latter version, the maximum rate of transport increase in the cyclonic part of the Gulf Stream at Cape Hatteras is also about $1.8 \mathrm{~Sv} / 10$ $\mathrm{km}$ in $10 \mathrm{~km}$ bins, similar to what is observed farther south.

The transports shown in Fig. 7 are summarized in Table 1 . The mean velocity in each layer $\bar{v}$, is computed simply by dividing the layer transport by the total cross-sectional area of the layer. One difficulty with the transport representation shown in Fig. 7 is that transport changes due to a constant barotropic 


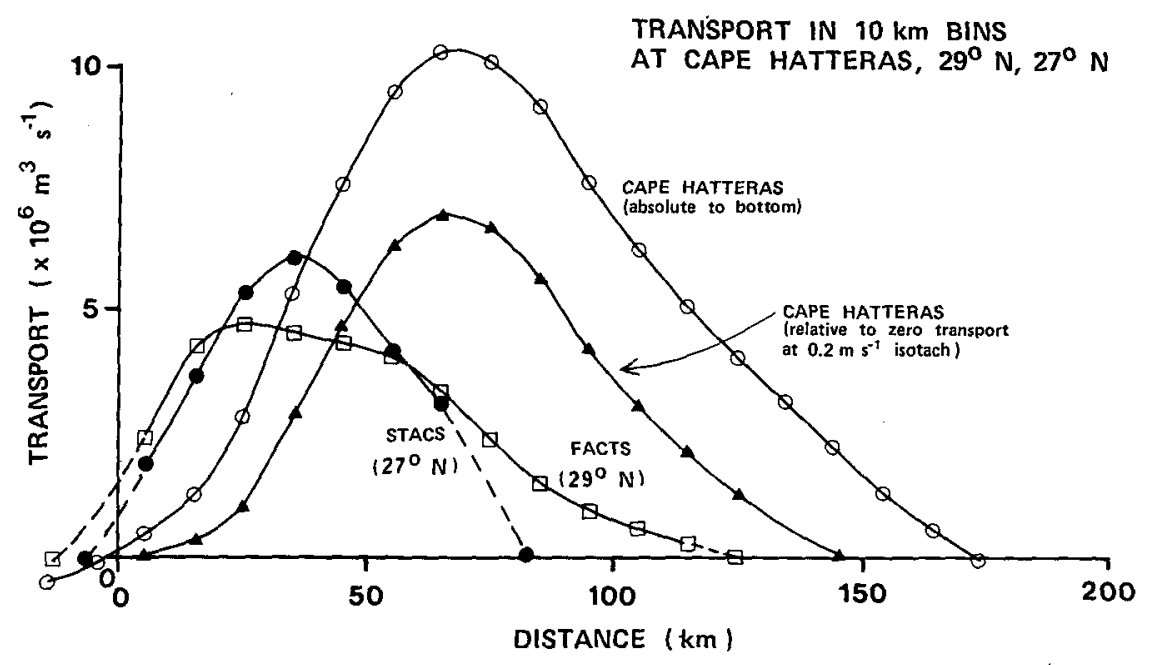

FIG. 8. Distribution of total average transport (in $10 \mathrm{~km}$ bins) with cross-stream distance at the three sections.

velocity component acting on a thicker or thinner layer are not resolved. For this reason, we have included in Table 1 the transport in each layer $\left(T_{B T / 20}\right)$ that would arise from a $0.2 \mathrm{~m} \mathrm{~s}^{-1}$ mean barotropic flow acting across the current. Of course there is no a priori reason why the barotropic velocity should be independent of cross-stream position; this value has again been chosen based on the observation (Fig. 4) that off Cape Hatteras, the strongly baroclinic current is mainly confined to isotachs greater than $0.2 \mathrm{~m} \mathrm{~s}^{-1}$. In particular, at the extreme offshore end of the Cape Hatteras section (Fig. $4 a)$, it is clear that the current is primarily barotropic but the depth-averaged velocities are actually less than $0.2 \mathrm{~m} \mathrm{~s}^{-1}$. Also, it is clear that the deep $\left(<7^{\circ} \mathrm{C}\right)$ flow is not strictly barotropic-the mean velocities observed in moving from the $4.5^{\circ}-7.0^{\circ}$ layer to the $2.0^{\circ}-4.5^{\circ}$ layer decrease from 0.13 to $0.04 \mathrm{~m} \mathrm{~s}^{-1}$. For this reason, the observed transports in these two deepest layers have been included as the barotropic component. Nevertheless, the $\bar{v}$ values observed at Cape Hatteras suggest that $0.2 \mathrm{~m} \mathrm{~s}^{-1}$ is not an unreasonable choice for a "reference" deep velocity immediately below the baroclinic core of the Gulf Stream. In particular, the mean velocity of the two layers immediately above and below the
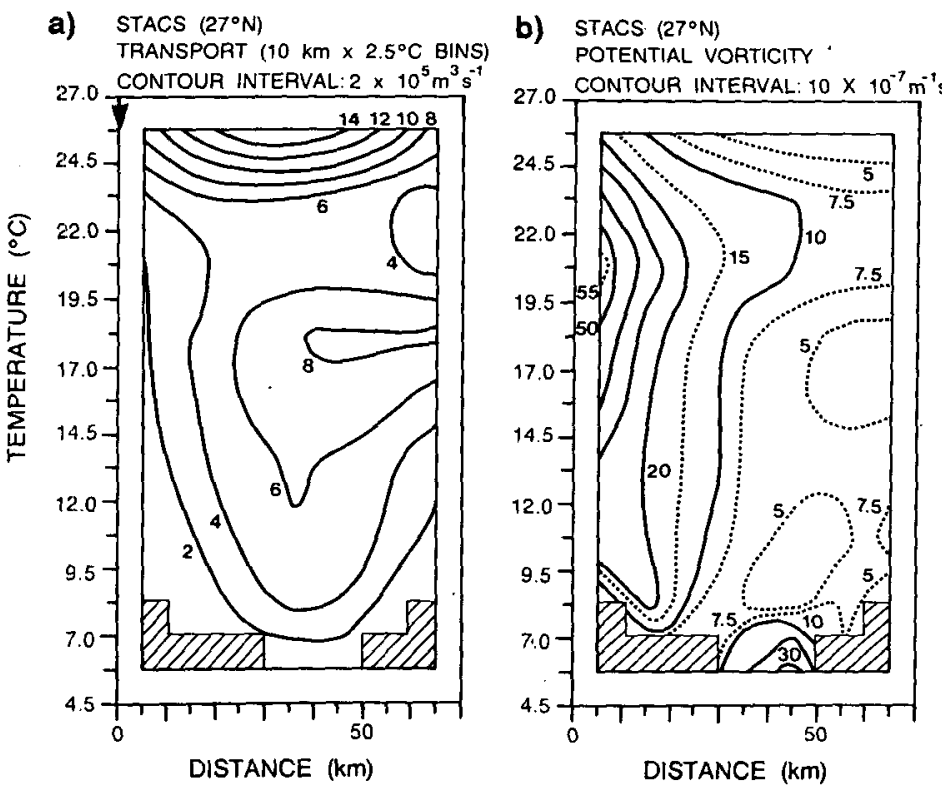

c) STACS $\left(27^{\circ} \mathrm{N}\right)$

THICKNESS

27.0 CONTOUR INTERVAL: $20 \mathrm{~m}$

FIG. 9. Contours of average transport in $10 \mathrm{~km} \times 2.5^{\circ} \mathrm{C}$ bins (a), layer potential vorticity (b), and thickness (c) across the Florida Current at $27^{\circ} \mathrm{N}$. 


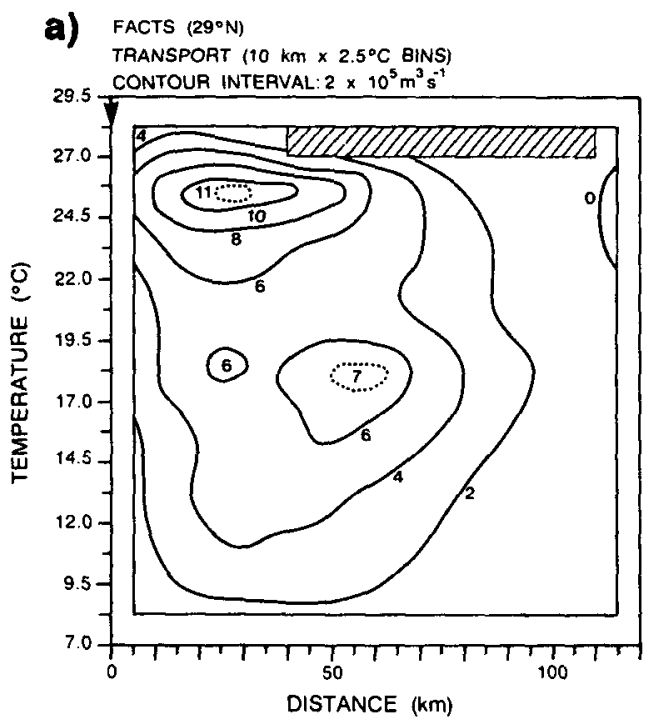

b) FACTS $\left(29^{\circ} \mathrm{N}\right)$

POTENTIAL VORTICITY

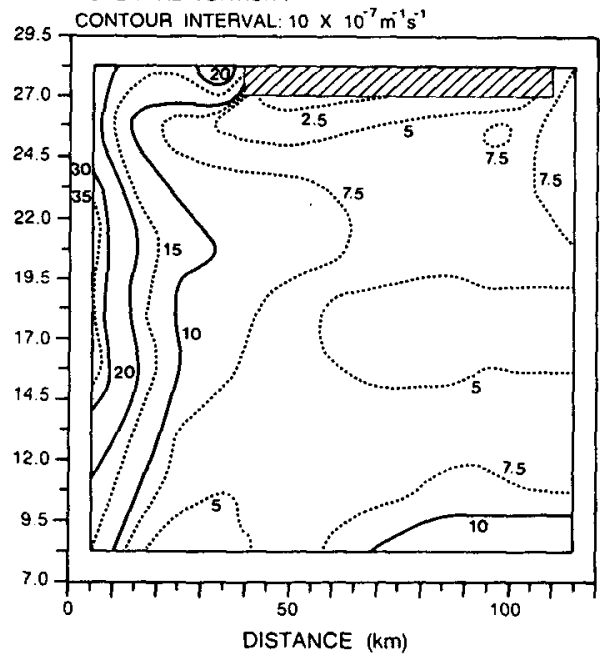

C) FACTS $\left(29^{\circ} \mathrm{N}\right)$

THICKNESS

29.5 CONTOUR INTERVAL: $20 \mathrm{~m}$

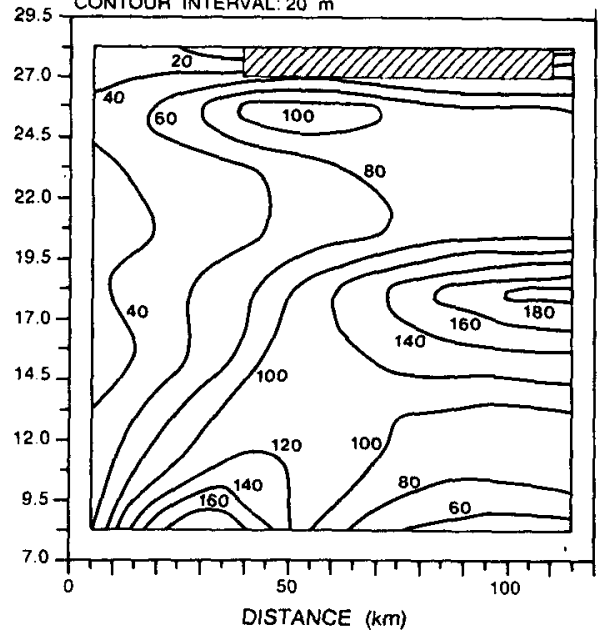

FIG. 10. As in Fig. 9 but at $29^{\circ} \mathrm{N}$. $7^{\circ} \mathrm{C}$ horizon is almost exactly this value. The last column in Table 1 compares the total observed transport increase between $27^{\circ} \mathrm{N}$ and Cape Hatteras to the 0.2 $\mathrm{m} \mathrm{s}^{-1}$ barotropic transports at Cape Hatteras. The most striking feature of this last column is that of the total difference (about $12 \mathrm{~Sv}$ ), fully two-thirds, or about 8 $\mathrm{Sv}$, is concentrated in the $18^{\circ}$ layer. Taken together, the results in the final two columns of Table 1 suggest that of the total increase in $18^{\circ}$-layer transport (15 Sv) observed between $27^{\circ} \mathrm{N}$ and Cape Hatteras, about 7 $\mathrm{Sv}$ arises simply from increased barotropic transport over a thicker layer, whereas about $8 \mathrm{~Sv}$ arises from an additional baroclinic transport in this layer. In section 7 , we will consider this transport in greater detail. [We should also note that from the totals indicated in Table 1 , one would infer that the "baroclinic" transport of the Gulf Stream at Cape Hatteras amounts to $42 \mathrm{~Sv}$ $(93.7$ - 51.7), whereas the direct computation from Fig. 8 gives 45.9 Sv. This discrepancy arises mainly because these two values were computed in a slightly different fashion-most of the $4 \mathrm{~Sv}$ difference occurs in the small region at Cape Hatteras where the $0.2 \mathrm{~m}$ $\mathrm{s}^{-1}$ isotach penetrates to levels colder than $7^{\circ} \mathrm{C}$ (Fig. 4).]

\section{Cross-stream distributions of transport, potential vorticity, and layer thickness versus temperature}

In this section, we examine the downstream structure of transport, potential vorticity, and layer thickness. Figures 9-11 show contours of transport (per $10 \mathrm{~km}$ $\times 2.5^{\circ} \mathrm{C}$ bin ), layer potential vorticity, and layer thickness computed in the manner described in section 4 at $27^{\circ}, 29^{\circ} \mathrm{N}$ and Cape Hatteras. In a few cases (indicated by cross-hatching), no water was present in the indicated $10 \mathrm{~km} \times 2.5^{\circ} \mathrm{C}$ bin. Where possible, contours were interpolated across these missing bins.

At $27^{\circ} \mathrm{N}$, the main effect of converting depth to temperature coordinates is to vertically align the nearsurface core of the Florida Current (Fig. 2a vs Fig. 9a). This core is bounded roughly by the $0.6 \times 10^{6} \mathrm{~m}^{3} \mathrm{~s}^{-i}$ transport contour. At colder levels, the most obvious transport feature is the presence of a maximum in the $18^{\circ}$ water, extending westward about $30 \mathrm{~km}$ into the channel. This layer reaches a thickness of about 140 $\mathrm{m}$ at the eastern boundary (Fig. 9c) and is associated with a clear minimum in layer potential vorticity (Fig. $9 b)$. Smallest values, about $3.4 \times 10^{-7} \mathrm{~m}^{-1} \mathrm{~s}^{-1}$, are found at the eastern boundary. However, relative to other parts of the current, layer potential vorticity tends to be relatively independent of cross-stream distance in the eastern half of the channel at $27^{\circ} \mathrm{N}$. The 10 $\times 10^{-7} \mathrm{~m}^{-1} \mathrm{~s}^{-1}$ contour separates the eastern region of relatively uniform potential vorticity from the western part (cyclonic flow) with large lateral potential vorticity gradients. Away from surface and bottom boundaries, the cross-stream location of this "boundary" contour is relatively independent of temperature. Consideration of the mean downstream velocity and 
a) CAPE hatteras

TRANSPORT $\left(10 \mathrm{~km} \times 2.5^{\circ} \mathrm{C}\right.$ BINS)

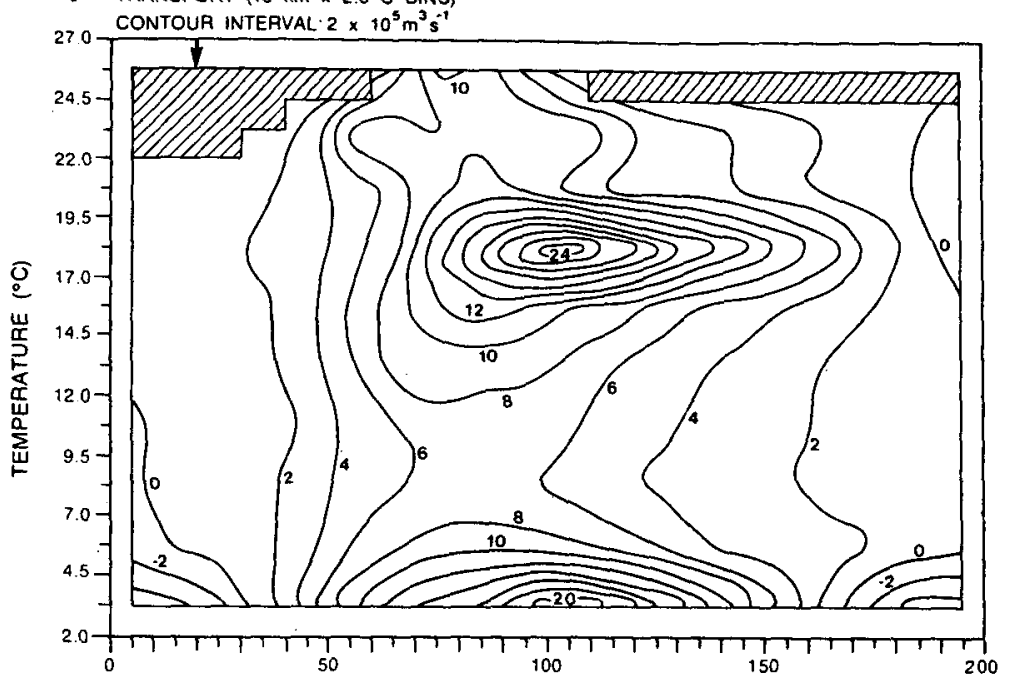

b) CAPE hatteras

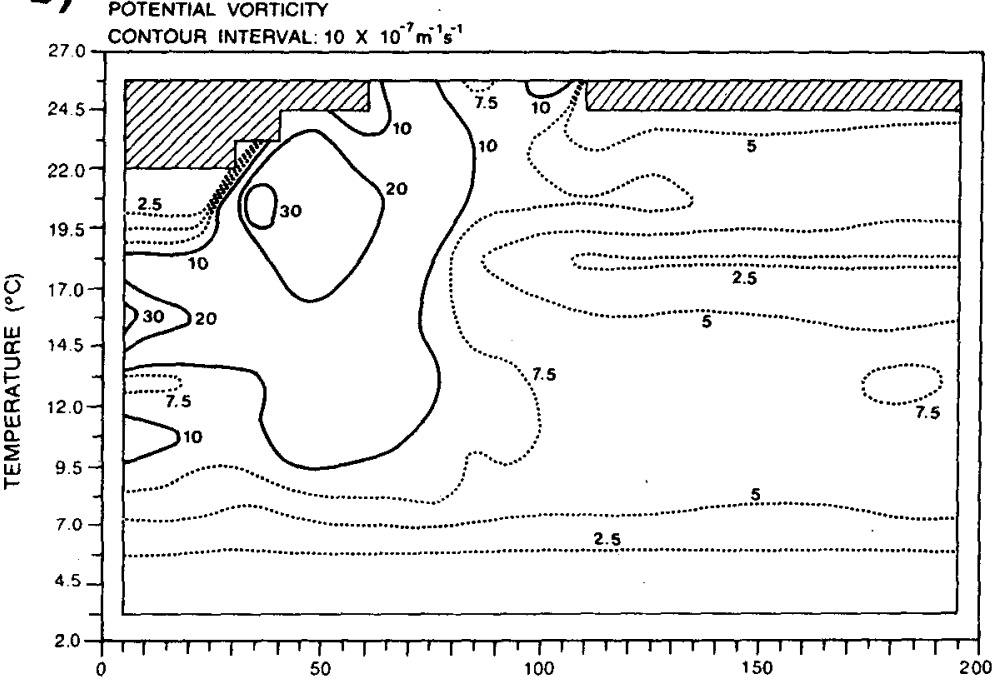

\section{C) CAPE HATTERAS}

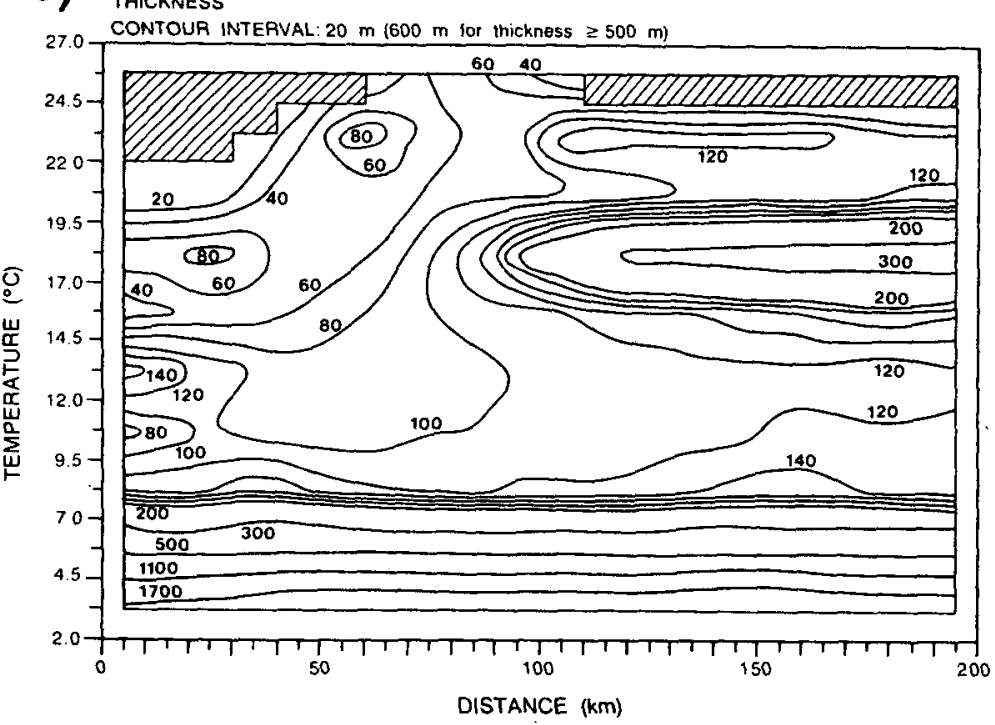

FiG. 11. As in Fig. 9 but off Cape Hatteras. 
temperature fields (Fig. 2) shows that this boundary is located for each temperature interval at about the point where the relative vorticity in the layer becomes cyclonic. We will see that a similar behavior is evident at $29^{\circ} \mathrm{N}$ and Cape Hatteras.

Compared to the mean structure at $27^{\circ} \mathrm{N}$, the tendency of the current at $29^{\circ} \mathrm{N}$ to spread eastward is evident in Fig. 10a-c. Taking into account the additional (warmer) temperature interval plotted at $29^{\circ} \mathrm{N}$, the surface core at both latitudes is, as would be expected, in about the same temperature range. At this latitude, the thickness of the $18^{\circ}$ water has increased to about $180 \mathrm{~m}$ and the east-west extent of this layer has increased. In view of Fig. 10c, it is somewhat surprising that $18^{\circ}$-layer transport increases only by 0.9 $\times 10^{6} \mathrm{~m}^{3} \mathrm{~s}^{-1}$ between $27^{\circ} \mathrm{N}$ and $29^{\circ} \mathrm{N}$. However, Fig. $10 \mathrm{a}$ shows that the transport in the eastern part of this layer is actually quite small. In general, the layer potential vorticity distribution at $29^{\circ} \mathrm{N}$ (Fig. $10 \mathrm{~b}$ ) is similar to that found at $27^{\circ} \mathrm{N}$ but spread out to the east. The minimum potential vorticity in the $18^{\circ}$ layer is again found to be about $3.5 \times 10^{-7} \mathrm{~m}^{-1} \mathrm{~s}^{-1}$ near the eastern boundary. The $10 \times 10^{-7} \mathrm{~m}^{-1} \mathrm{~s}^{-1}$ contour once more separates regions of uniform and high-lateral-gradient potential vorticity. In the middle of the water column the cross-stream location of this "boundary" is relatively independent of temperature.

The total amount of warm surface waters transported on average at Cape Hatteras is similar to that observed at $27^{\circ}$ and $29^{\circ} \mathrm{N}$, but heat losses to the atmosphere have led to a water mass transformation from waters warmer than $24.5^{\circ} \mathrm{C}$ to waters cooler than $24.5^{\circ} \mathrm{C}$. The large increases in transport within the $18^{\circ}$ layer and for layers colder than $7^{\circ} \mathrm{C}$ are evident from Fig. 11a. Maximum thickness of the $18^{\circ}$ layer has increased to over $300 \mathrm{~m}$, and the layer potential vorticity minimum at the eastern boundary $\left(2.3 \times 10^{-7} \mathrm{~m}^{-1} \mathrm{~s}^{-1}\right)$ is smaller than values observed farther south; the increase (decrease) in layer thickness (potential vorticity) is consistent with the proximity of this section to the winter formation region of $18^{\circ}$ water (Leetmaa 1977). However in the $18^{\circ}$-layer "core", or region of highest transport (at about $100 \mathrm{~km}$ distance in Fig. 11a), potential vorticity is very similar $\left(3.4 \times 10^{-7} \mathrm{~m}^{-1} \mathrm{~s}^{-1}\right)$ to minimum values seen farther south. Below $7^{\circ} \mathrm{C}$, potential vorticity is quite uniform across the Gulf Stream at about $5 \times 10^{-7} \mathrm{~m}^{-1} \mathrm{~s}^{-1}$. (Coldest in situ temperatures in the Cape Hatteras section are $2.1^{\circ}-2.2^{\circ} \mathrm{C}$ ). As observed to the south, the $10 \times 10^{-7} \mathrm{~m}^{-1} \mathrm{~s}^{-1}$ contour separates the eastward region of relatively uniform layer potential vorticity from the high-gradient region to the west, but only for the layers $9.5^{\circ}-12^{\circ} \mathrm{C}$ and above. The cross-stream position of this contour is relatively independent of temperature for layers warmer than about $10^{\circ} \mathrm{C}$. Comparison of Fig. $11 \mathrm{c}$ with Figs. $11 \mathrm{a}$ and $11 \mathrm{~b}$ also indicates that this same potential vorticity contour marks the westernmost penetration of the $18^{\circ}$ layer.
Taken together, Figs. 9-11 provide an opportunity to examine the downstream evolution of transport and particularly of potential vorticity (including relative vorticity) in the Gulf Stream. There are some obvious differences, as well as certain striking similarities, in the three sections.

One obvious similarity is the tendency of the 10 $\times 10^{-7} \mathrm{~m}^{-1} \mathrm{~s}^{-1}$ layer potential vorticity contour (Figs. 9-11b) to serve as a boundary between the high-velocity, cyclonic core of the Gulf Stream and water farther offshore. At both $27^{\circ}$ and $29^{\circ} \mathrm{N}$ the current is bounded on the west by the continental shelf; thus the high potential vorticities encountered in cyclonic flow near the western boundary are perhaps not surprising. However, this observation does not explain why this particular value of layer potential vorticity separates regions of relatively uniform potential vorticity (offshore) from regions of high lateral potential vorticity gradient (onshore). Between $27^{\circ}$ and $29^{\circ} \mathrm{N}$ this contour does not move appreciably to the east; most of the current broadening (Fig. 8) takes place in the offshore region of relatively uniform layer potential vorticity.

At Cape Hatteras the same contour tends to be a boundary (Fig. 11b), but only above a certain temperature horizon (about $10^{\circ} \mathrm{C}$ ). This same horizon is near (but slightly warmer than) the temperature boundary between warmer layers (but below $18^{\circ} \mathrm{C}$ ) where the transport increase between $29^{\circ} \mathrm{N}$ and Cape Hatteras is relatively uniform at about $4.0-4.5 \mathrm{~Sv}$ per $2.5^{\circ} \mathrm{C}$ interval, and colder layers $\left(<7^{\circ} \mathrm{C}\right)$ where no transport is present south of Cape Hatteras (Fig. 7). McCartney (1982, Fig. 3) has presented a potential vorticity section along $50^{\circ} \mathrm{W}$ through the Gulf Stream, using potential density as the vertical coordinate but without the inclusion of relative vorticity. Although this is quite far downstream of the present Cape Hatteras section, it is of interest that he also shows a similar potential vorticity boundary at a value of about 200 $\times 10^{-14} \mathrm{~cm}^{-1} \mathrm{~s}^{-1}$. [For a $2.5^{\circ} \mathrm{C}$ layer below $18^{\circ} \mathrm{C}, \Delta \sigma_{\theta}$ $\sim 0.20-0.25$ (Fig. 6). Applying the conversion described in section 4 , a layer potential vorticity of 10 $\times 10^{-7} \mathrm{~m}^{-1} \mathrm{~s}^{-1}$ is equivalent to $(200-250) \times 10^{-14}$ $\mathrm{cm}^{-1} \mathrm{~s}^{-1}$ ]. Of course, the increase of layer potential vorticity (contributed by increasing relative cyclonic vorticity as one moves into the current core from offshore) is not evident in his figure-in fact, the 200 $\times 10^{-14} \mathrm{~cm}^{-1} \mathrm{~s}^{-1}$ contour appears to be the boundary of a potential vorticity "plateau" in the cyclonic part of the current core.

One of the most striking contrasts among the sections appears in the $18^{\circ}$ layer. Various investigators (e.g., McDowell et al. 1982; McCartney 1982; Talley and McCartney 1982; Talley and Raymer 1982; McCartney and Talley 1982) have attempted to use potential vorticity as a conservative tracer to follow various types of subpolar (e.g., Labrador Sea) or subtropical (such 
as $18^{\circ}$ water) "Mode Waters". The low potential vorticity associated with the relatively thick layer of $18^{\circ}$ water in the North Atlantic has been well documented in these studies (e.g., McCartney 1982), although in contrast to the data discussed here, the reliance of these studies on hydrographic data has not allowed the contributions to potential vorticity by the relative vorticity term to be evaluated. If we accept that the low potential vorticity in the $18^{\circ}$-layer serves as a tracer, Fig. 9b suggests that a small amount of $18^{\circ}$ water (from Fig. 7 probably no more than about $1 \mathrm{~Sv}$ ) is recirculated through the Straits of Florida and is confined to the eastern edge of the current. This possibly represents part of the inflow of water to the Florida Current through Northwest Providence Channel reported by Richardson and Finlen (1967). However, others (Morrison and Nowlin 1977) have found intermittent indications of $18^{\circ}$ water (identified by a relative oxygen maximum ) upstream in the Loop Current of the Gulf of Mexico. As shown in Fig. 7, transport in the $18^{\circ}$ layer increases only by about another $1 \mathrm{~Sv}$ between $27^{\circ}$ and $29^{\circ} \mathrm{N}$.

In proceeding from $29^{\circ} \mathrm{N}$ to Cape Hatteras, transport in the $18^{\circ}$ layer increases by another $13.7 \mathrm{~Sv}$, reaching 19.1 Sv at Cape Hatteras. From hydrographic data, Worthington (1976) provided an estimate of $14.2 \mathrm{~Sv}$ for the $17^{\circ}-19^{\circ} \mathrm{C}$ layer transport off Cape Hatteras. Although our estimate is about $35 \%$ higher, it must be kept in mind, first, that we are using a slightly larger temperature interval, but second and more important, long-term variations in $18^{\circ}$ water are known to exist (Talley and Raymer 1982).

The region in which the large transport increase of $18^{\circ}$ water originally noted by Worthington (1976) is concentrated can be seen in Fig. 11, as well as several other features of the $18^{\circ}$ layer. Most clear is the fact that the thick (and therefore low potential vorticity) $18^{\circ}$ layer is primarily restricted to the region of the Gulf Stream offshore of the same $10 \times 10^{-7} \mathrm{~m}^{-1} \mathrm{~s}^{-1}$ potential vorticity boundary discussed above. Also, most of the elevated transport in this layer is concentrated at the "nose" in layer thickness at $100-110 \mathrm{~km}$ horizontal distance. Farther offshore (e.g., at $150 \mathrm{~km}$ ), transport and layer thickness tend to be proportional if one examines the $17^{\circ}-19.5^{\circ}$ layer and those immediately above and below, suggesting that at the offshore end of the $18^{\circ}$ "bullseye" (Fig. 11a), transport is primarily barotropic. The same is not true in the immediate vicinity of the "bullseye", where there is an additional baroclinic transport component present. In the next section, we will present a simple model that seeks to account in a semiquantitative fashion for the observed transport and thickness structure in the $18^{\circ}$ layer.

Below $7^{\circ} \mathrm{C}$, layer potential vorticity is quite uniform horizontally and is comparable to values obtained by others (McDowell et al. 1982). In terms of water mass properties in these colder layers, the Gulf Stream appears to be well stirred from one side to the other, leading to spatial homogeneity (Bower et al. 1985). This is not to say there is no baroclinicity and concomitant downstream flow, but such flow may not be constrained to remain in the Gulf Stream over great distances due to the absence of a mean potential vorticity gradient across the stream (Shaw and Rossby 1984; Rossby et al. 1985).

\section{Structure of the $18^{\circ}$ layer}

In this section, we wish to use a simple model to focus qualitatively on the baroclinic component of the transport structure in the $18^{\circ}$ layer off Cape Hatteras. This structure is very reminiscent of that found in a simple two-layer model of the Gulf Stream by Stommel (1965), as well as in an analysis presented by Stern (1975, pp. 53-57).

We assume the $18^{\circ}$ layer to be one of uniform density $\rho_{2}$, sandwiched between two layers of density $\rho_{1}$ and $\rho_{3}$ (Fig. 12a). Here, $\rho_{2}-\rho_{1}=\rho_{3}-\rho_{2}=\Delta \rho$. For simplicity, and because we wish to focus on the baroclinic transport within layer 2, we assume that layers 1 and 3 are motionless and are essentially of infinite thickness relative to layer 2 .

If $H$ is the thickness of the middle layer and flow $(v)$ in the layer is in geostrophic balance and independent of downstream distance, then

$$
f v=g^{\prime} \frac{d H}{d x}
$$

where $x$ is the coordinate to the right of the flow, $g^{\prime}$ is reduced gravity, $\rho_{0}$ is a constant reference density and $f\left(=8.5 \times 10^{-5} \mathrm{~s}^{-1}\right.$ at Cape Hatteras $)$ is the Coriolis parameter. We assume that $H=0$ at $x=0$ (corresponding to the location of the "nose" in Fig. 11c), and as $x \rightarrow \infty, H \rightarrow H_{0}$ (const) and $v \rightarrow 0$. Conservation of potential vorticity in the layer requires that

$$
\frac{f}{H_{0}}=\frac{f+d v / d x}{H(x)}
$$

a)

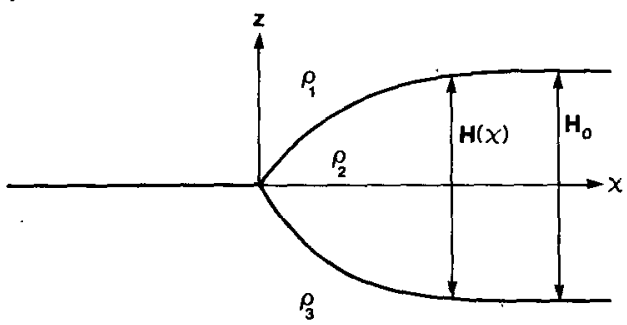

FIG. 12a. Schematic of a simple model for flow in the " $18^{\circ}$-layer" with three layers of constant densities $\rho_{1}, \rho_{2}$ and $\rho_{3}$. Layers 1 and 3 are assumed motionless. Layer 2 is assumed to have constant potential vorticity with magnitude $f / H_{0}$ at large $x$. 
b)

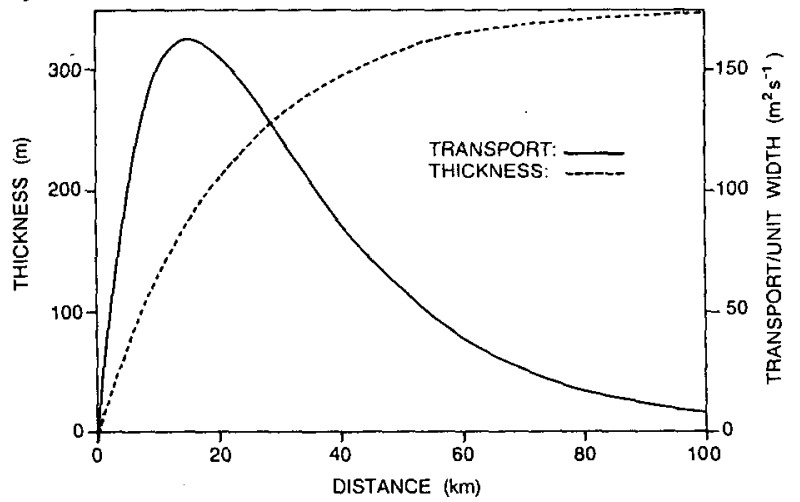

Fig. 12b. Curves describing the thickness and volume transport/ unit width across the current in layer 2 , with $H_{0}=350 \mathrm{~m}, f=8.5$ $\times 10^{-5} \mathrm{~s}^{-1}$, and $\Delta \rho / \rho_{0}=10^{-3} \Delta \sigma_{\theta}=1 \times 10^{-3}$.

Equations (8) and (9) can be combined for a single equation for $H$ :

$$
\frac{d^{2} H}{d x^{2}}-\frac{H-H_{0}}{\lambda^{2}}=0
$$

where $\lambda=\sqrt{g^{\prime} H_{0}} / f$ is the internal radius of deformation. Given the above boundary conditions, Eq. (10) has as solutions for layer thickness $(H)$, velocity $(V)$, layer transport per unit width $\left(T_{w}=H V\right)$, and total transport $(T)$ :

$$
\begin{aligned}
H(x) & =H_{0}\left(1-e^{-x / \lambda}\right) \\
v(x) & =\sqrt{g^{\prime} H_{0}} e^{-x / \lambda} \\
T_{w}(x) & =H_{0} \sqrt{g^{\prime} H_{0}}\left(e^{-x / \lambda}-e^{-2 x / \lambda}\right) \\
T & =\int_{0}^{\infty} T_{w}(x) d x \\
& =\lambda H_{0} \sqrt{g^{\prime} H_{0}} / 2=g^{\prime} H_{0}{ }^{2} / 2 f .
\end{aligned}
$$

In this simple 3-layer model, we can use Fig. 6 (with a slight bit of fudging) to estimate the $18^{\circ}$ layer density as $\sigma_{\theta}=26.5$, and the densities of layers 1 and 3 by the average of $\sigma_{\theta}$ values above $\left(\sigma_{\theta} \sim 25.5\right)$ and below $\left(\sigma_{\theta}\right.$ $\sim 27.5$ ) the $18^{\circ}$ layer. From Fig. $11 \mathrm{c}$, we take $H_{0}=350$ $\mathrm{m}$. For this choice of parameters, $g^{\prime}=9.81 \times 10^{-3} \mathrm{~m}$ $\mathrm{s}^{-2}$, and $\lambda=21.8 \times 10^{3} \mathrm{~m}$. The structure of $T_{w}(x)$ and $H(x)$ is shown in Fig. $12 \mathrm{~b}$ for the above choice of parameters. Substituting these values in Eq. (11d) gives a total baroclinic transport of $T=7.1 \times 10^{6} \mathrm{~m}^{3} \mathrm{~s}^{-1}$.

The over-simplified model discussed above does a reasonable job of describing some of the observed features of the $18^{\circ}$ layer (Fig. 11) off Cape Hatteras. For example, the rapid increase in transport/unit width (Fig. 1 la, with actual values in units of transport/10 $\mathrm{km}$ width) at the "nose" of this layer, and the gradual decrease in transport as one moves offshore, are quite similar to the result shown in Fig. 12b. The width of the observed transport "bullseye" is somewhat more difficult to estimate. We can take, for example, the 7 $\times 10^{5} \mathrm{~m}^{3} \mathrm{~s}^{-1}$ contour (Fig. 11a) as defining the lateral boundaries of the transport peak. (This value corresponds to a constant flow of $0.2 \mathrm{~m} \mathrm{~s}^{-1}$ through a 10 $\mathrm{km} \times 350 \mathrm{~m}$ box and is chosen to be consistent with the results shown in Table 1 . Note, however, that at the far offshore end of the Cape Hatteras section, transports in the $18^{\circ}$ layer are actually somewhat less.) With this choice, the "detectable" width of the peak is about $100 \mathrm{~km}$ and the "half-amplitude" width of the peak [between the $(7+(24-7) / 2) \times 10^{5} \mathrm{~m}^{3} \mathrm{~s}^{-1}=15.5$ $\times 10^{5} \mathrm{~m}^{3} \mathrm{~s}^{-1}$ points in Fig. 11a] is about $50 \mathrm{~km}$ (the corresponding width in Fig. $12 \mathrm{~b}$ is about $40 \mathrm{~km}$ ). Also, the value of total baroclinic transport in the layer computed from the model $(7 \mathrm{~Sv})$ is in reasonable agreement with the estimated baroclinic transport ( $8 \mathrm{~Sv}$ ) shown in Table 1. Nevertheless, the gross simplifications involved in the model should be kept in mind. In particular, the shallower $\left(T>18^{\circ} \mathrm{C}\right)$ layers of the Gulf Stream are not infinitely deep (Fig. 4b) but are in fact of comparable thickness to the $18^{\circ}$ layer itself. We would therefore expect there to be some interaction between the $18^{\circ}$ layer and those above, and we speculate that this may be one cause of the clear asymmetry seen in the transport contours (Fig. 11a), where the shallow contours tend to open toward the surface, whereas the same contours below the $18^{\circ}$ layer remain closed. However, to describe such features would clearly require a more detailed model than that used here.

One final point to be made concerning the model is that the choice of origin $(x=0)$ is completely arbitrary. The data suggest that the origin should be placed at the point where the onshore layer potential vorticity gradient begins to increase rapidly towards the cyclonic part of the current. However, the model does not (and is not intended to) explain why this should be the case.

\section{Summary}

Annually averaged or mean cross sections of absolute downstream velocity and temperature have been presented at three downstream locations across the Florida Current and Gulf Stream. Between the two southern cross sections $\left(27^{\circ} \mathrm{N}, 29^{\circ} \mathrm{N}\right)$ and the third section at Cape Hatteras the total transport increases by a factor of three. Two-thirds of the increase is located in (i) the $18^{\circ}$ layer water, and (ii) in water colder than $7^{\circ} \mathrm{C}$ the coldest water found in the Straits of Florida. From $7^{\circ}$ to $14.5^{\circ} \mathrm{C}$ the transport increase between $27^{\circ} \mathrm{N}$ and Cape Hatteras is quite uniform at about $4.5 \mathrm{~Sv}$ per $2.5^{\circ} \mathrm{C}$ temperature interval. 
As a function of horizontal distance across the Gulf Stream (Fig. 8), the transport increase on the cyclonic side of the current is relatively constant at about 1.8 $\mathrm{Sv} / 10 \mathrm{~km}$ for each section. More surprisingly, when Cape Hatteras transport is referenced to the $0.2 \mathrm{~m} \mathrm{~s}^{-1}$ isotach (suggested by the barotropic character of the flow below this isotach), the transport curve at Cape Hatteras looks quite similar, both in magnitude and width, to that observed in the Florida Current (allowing for an arbitrary shift of the horizontal distance origin ).

Potential vorticity computed over $2.5^{\circ} \mathrm{C}$ layers shows a relative minimum in the $18^{\circ}$ layer at the offshore end of each section. This layer penetrates into the anticyclonic part of the Gulf Stream at each section (but most clearly at Cape Hatteras near where $18^{\circ} \mathrm{C}$ water is formed in wintertime), and has a transport peak in the region of maximum penetration. A simple, geostrophically balanced model can reproduce qualitatively the observed structure of layer transport and thickness. At each section the $10 \times 10^{-7} \mathrm{~m}^{-1} \mathrm{~s}^{-1}$ layer potential vorticity contour (including relative vorticity) appears as a distinctive boundary separating the highpotential-vorticity, cyclonic current core from a region of more uniform potential vorticity farther offshore. The $18^{\circ}$ layer (as identified by its potential vorticity minimum) does not penetrate onshore of this boundary. Below about $7^{\circ} \mathrm{C}$ potential vorticity is practically uniform across the width of the current at Cape Hatteras, supporting other work which has suggested that in the deep layers relatively free exchange of fluid can take place across the Gulf Stream. The clear distinction in properties above and below $7^{\circ} \mathrm{C}$ off Cape Hatteras, in association with the $7^{\circ} \mathrm{C}$ "sill" temperature in the Straits of Florida, suggests that it would be worthwhile to obtain similar absolute velocity sections across the Kuroshio, where the topography along the path of the current differs considerably from the Gulf Stream.

Acknowledgments. We wish to thank the officers and crews of the Research Vessels Endeavor (University of Rhode Island Graduate School of Oceanography), Cape Florida and Calanus (University of Miami Rosenstiel School of Marine and Atmospheric Science), Researcher (NOAA Atlantic Oceanographic and Meteorological Laboratories) and Suncoaster (Florida Institute of Oceanography) for their assistance in collecting these data. We also thank the University of Rhode Island and University of Miami shipboard technician groups for their support in keeping the equipment running, and Mr. Peter Vertes of University of Miami for his help in the data analysis. Dr. Johns received support from the National Oceanic and Atmospheric Administration through the Cooperative Institute for Marine and Atmospheric Studies (Cooperative Agreement NA85WC-H-06134). The analysis of these data was supported by the Office of Naval Research under Contract N00014-85-C-0020.

\section{REFERENCES}

Bower, A. S., H. T. Rossby and J. L. Lillibridge, 1985: The Gulf Stream-Barrier or blender? J. Phys. Oceanogr., 15, 24-32.

Ertel, H., 1942: Ein neuer hydrodynamischer Wirbelsatz. Meteor. Z., 59, 277-281.

Halkin, D., and T. Rossby, 1985: The structure and transport of the Guif Stream at $73^{\circ}$ W. J. Phys. Oceanogr., 15(11), 1439-1452.

Iselin, C. O'D., 1940: Preliminary report on long-period variations in the transport of the Gulf Stream system. Pap. Phys. Oceanogr. Meteor., 8(1), $40 \mathrm{pp}$.

Johns, W., and F. Schott, 1987: Meandering and transport variations of the Florida Current. J. Phys. Oceanogr., 17, 1128-1147.

Larsen, J. C., and T. B. Sanford, 1985: Florida Current volume transports from voltage measurements. Science, 227, 302-304.

Leaman, K. D., 1986: Florida Atlantic Coast Transport Study (FACTS): PEGASUS Data. Final Rep. to U.S. Dept. of Interior, $59 \mathrm{pp}$.

- and R. L. Molinari, 1987a: Topographic modification of the Florida Current by Little Bahama and Great Bahama Banks. $J$. Phys. Oceanogr., 17(10), 1724-1736.

$-1-$ and P.S. Vertes, 1987b: Structure and variability of the Florida Current at $27^{\circ} \mathrm{N}$ : April 1982-July 1984. J. Phys. Oceanogr., 17(5), 565-583.

Lee, T. N., F. Schott and R. Zantopp, 1985: Florida Current: Lowfrequency variability of the Florida Current as observed with moored current meter stations during April 1982-June 1983. Science, 227, 298-301.

Leetmaa, A., 1977: Effects of the winter of 1976-1977 on the northwestern Sargasso Sea. Science, 198, 188-189.

McCartney, M. S., 1982: The subtropical recirculation of mode waters. J. Mar. Res., 40(Suppl.), 427-464.

—, and L. D. Talley, 1982: The subpolar mode water of the North Atlantic Ocean. J. Phys. Oceanogr., 12, 1169-1 188.

McDowell, S., P. Rhines and T. Keefer, 1982: North Atlantic potential vorticity and its relation to the general circulation. J. Phys. Oceanogr., 12, 1417-1436.

McWilliams, J. C., 1983: On the mean dynamical balances in the Gulf Stream recirculation zone. J. Mar. Res., 41, 427-460.

Maul, G. A., 1985: FACTS: The Florida Atlantic Coast Transport Study. Eos Trans. Amer. Geophys. Union, 66, 434.

- , F. Chew, M. Bushnell and D. Mayer, 1985: Florida Current: Sea level variation as an indicator of volume transport-Comparisons with direct measurements. Science, 277, 304-307.

Mayer, D. A., K. D. Leaman and T. N. Lee, 1984: Tidal motions in the Florida Current. J. Phys. Oceanogr., 14(10), 1551-1559.

MODE-I Atlas Group, 1977: Atlas of the Mid-Ocean Dynamics Experiment (MODE-I). MIT Press, $274 \mathrm{pp}$.

Molinari, R. L., 1983: STACS: Subtropical Atlantic Climate Studies. Eos, Trans. Amer. Geophys. Union, 64(2).

- G. A. Maul, F. Chew, W. D. Wilson, M. Bushnell, D. Mayer, K. Leaman, F. Schott, T. Lee, R. Zantopp, J. C. Larsen and T. B. Sanford, 1985a: Subtropical Atlantic climate studies: Introduction. Science, 227, 295-297.

- W. D. Wilson and K. D. Leaman, 1985b: Volume and heat transports of the Florida Current: April 1982 through August 1983. Science, 227, 295-297.

Morrison, J. M., and W. D. Nowlin, Jr., 1977: Repeated nutrient, oxygen, and density sections through the Loop Current. J. Mar. Res., 35(1), 105-128.

Pillsbury, J. E., 1891: The Gulf Stream. Rep. U.S. Coast Geod. Survey for 1890, App. No. 10, 461-620.

Rago, T. A., and H. T. Rossby, 1987: Heat transport into the North Atlantic Ocean north of $32^{\circ} \mathrm{N}$ latitude. J. Phys. Oceanogr., 17(7), 854-871.

Richardson, W. S., and W. J. Schmitz, Jr., 1965: A technique for the direct measurement of transport with application to the Straits of Florida. J. Mar. Res., 23, 172-185.

- and J. R. Finlen, 1967: The transport of Northwest Providence Channel. Deep-Sea Res., 14, 361-367. 
—-, W. J. Schmitz, Jr. and P. P. Niiler, 1969: The velocity structure of the Florida Current from the Straits of Florida to Cape Fear. Deep-Sea Res., 16(Suppl.), 225-234.

Rossby, T., 1987: On the energetics of the Gulf Stream at 73W. $J$. Mar. Res., 45, 59-82.

- A. S. Bower and P. T. Shaw, 1985: Particle pathways in the Gulf Stream. Bull. Amer. Meteor. Soc., 66, 1106-1110.

Schmitz, W. J., and W. S. Richardson, 1968: On the transport of the Florida Current. Deep-Sea Res., 15, 679-693.

Schott, F., and R. Zantopp, 1985: Florida Current: Seasonal and interannual variability. Science, 227, 308-311.

Shaw, P. T., and H. T. Rossby, 1984: Towards a Lagrangian description of the Gulf Stream. J. Phys. Oceanogr., 14, 528-540.

Spain, P. F., D. L. Dorson and H. T. Rossby, 1981: PEGASUS: A simple, acoustically-tracked velocity profiler. Deep-Sea Res. 28A, 1553-1567.
Stern, M. E., 1975: Ocean Circulation Physics. Academic Press, 246 pp.

Stommel, H., 1965: The Gulf Stream: A Physical and Dynamical Description. University of California Press, $248 \mathrm{pp}$.

Talley, L. D., and M. S. McCartney, 1982: Distribution and circulation of Labrador Sea Water. J. Phys. Oceanogr., 12, 11891205.

- and M. E. Raymer, 1982: Eighteen degree water variability. $J$. Mar. Res., 40(Suppl.), 757-775.

Worthington, L. V., 1976: On the North Atlantic Circulation. The Johns Hopkins Oceanographic Studies, No. 6, 110 pp.

Zantopp, R. J., and K. D. Leaman, 1984: The feasibility of dynamic height determination from moored temperature sensors. J. Phys. Oceanogr., 14(8), 1399-1406.

_ and T. N. Lee, 1987: Florida Current meanders: A close look in June-July 1984. J. Phys. Oceanogr., 17(5), 584-595. 